This document is the accepted manuscript version of the following article:

Edwards, T. E. J., Di Gioacchino, F., Goodfel1ow, A. J., Mohanty, G., Wehrs, J., Michler, J., \& Clegg, W. J. (2019). Deformation of lamellar Y-TiAl below the general yield stress. Acta Materialia, 163, 122-139. https://doi.org/10.1016/j.actamat.2018.09.061

\title{
Deformation of lamellar $\gamma$-TiAl below the general yield stress
}

Thomas Edward James Edwards $\mathbf{s}^{\mathbf{a}, 1}$ Corresponding author (teje2@cam.ac.uk)

Fabio Di Gioacchino ${ }^{a} \quad(f d 302 @$ cam.ac.uk $)$

Amy Jane Goodfellow ${ }^{\mathbf{a}} \quad$ (ajg210@cam.ac.uk)

Gaurav Mohanty ${ }^{\mathbf{b}, 2} \quad$ (gaurav.mohanty@tut.fi)

Juri Wehrs $^{\mathbf{b}} \quad$ (juri.wehrs@empa.ch)

Johann Michler ${ }^{\mathbf{b}} \quad$ (johann.michler@empa.ch)

William John Clegga $\quad$ (wjc1000@cam.ac.uk)

${ }^{a}$ Department of Materials Science and Metallurgy, 27 Charles Babbage Rd, University of Cambridge, Cambridge CB3 OFS, UK

${ }^{b}$ Empa, Swiss Federal Laboratories for Materials Science and Technology, Laboratory for Mechanics of Materials and Nanostructures, Feuerwerkerstrasse 39, 3602 Thun, Switzerland

\section{Abstract (250 words).}

The occurrence of plasticity below the macroscopic yield stress during tensile monotonic loading of nearly lamellar Ti-45Al-2Nb-2Mn(at\%)-0.8vol\% $\mathrm{TiB}_{2}$ at both $25{ }^{\circ} \mathrm{C}$ and $700{ }^{\circ} \mathrm{C}$, and in two conditions of lamellar thickness, was measured by digital image correlation strain mapping of a remodelled Au surface speckle pattern. Such initial plasticity, not necessarily related to the presence of common stress concentrators such as hard particles or cracks, could occur at applied stresses as low as $64 \%$ of the general yield stress. For a same applied strain it was more prominent at room temperature, and located as slip and twinning parallel to, and near to or at (respect.) lamellar interfaces of all types in soft modeoriented colonies. These stretched the full colony width and the shear strain was most intense in the

${ }^{1}$ Current address: Empa, Swiss Federal Laboratories for Materials Science and Technology, Laboratory for Mechanics of Materials and Nanostructures, Feuerwerkerstrasse 39, 3602 Thun, Switzerland

${ }^{2}$ Current address: Laboratory of Materials Science, Tampere University of Technology, P.O. Box 589, 33101 Tampere, Finland 
centre of the colonies. Further, the most highly operative microbands of plasticity at specimen fracture were not those most active prior to yielding. The strain mapping results from polycrystalline tensile loading were further compared to those from microcompression testing of soft-mode stacks of lamellae milled from single colonies performed at the same temperatures. Combined with post-mortem transmission electron microscopy of the pillars, the initial plasticity by longitudinal dislocation glide was found to locate within $30-50 \mathrm{~nm}$ of the lamellar interfaces, and not at the interfaces themselves. The highly localised plasticity that precedes high cycle fatigue failure is therefore inherently related to the lamellar structure, which predetermines the locations of plastic strain accumulation, even in a single loading cycle.

Keywords Titanium aluminide, electron backscattering diffraction (EBSD), digital image correlation, deformation twinning, pre-yield plasticity. 


\section{Introduction}

The widespread use of lightweight TiAl alloys as a replacement for steels and superalloys in engineering applications is limited by its fatigue behaviour. The high value of the Paris coefficient means that a small increase in the stress intensity factor results in a large increase in the crack growth rate, compared with standard engineering alloys. One approach is to operate components below the fatigue threshold of the TiAl alloy. Across a range of compositions and microstructural conditions, the stress at which this occurs is approximately $80 \%$ of the ultimate tensile stress [1], so that even in the absence of stress concentrators such as hard particles or cracks, the material experiences loading close to its general yield stress for $10^{7}$ cycles.

Early work on lamellar two-phase TiAl alloys, using polysynthetically twinned crystals [2-4], identified a considerable temperature-invariant anisotropy in the uniaxial flow stress, depending on the orientation of the lamellar planes to the loading axis, with the softest having a yield stress approximately one quarter that of the hardest. From this, it is not surprising therefore that Jiang et al. [5,6] detected microplasticity at room temperature in nearly lamellar Ti-44Al-8Nb-1B (at.\%) polycrystals at stresses as low as $400 \mathrm{MPa}$ for a $0.2 \%$ proof stress of $625 \mathrm{MPa}$, based on acoustic emission. The orientation of some colonies are such that the Schmid factors may be sufficiently high to cause localised yielding at only $65 \%$ of the general yield stress. Furthermore, though the spatial resolution was relatively low, micro-scale digital image correlation ( $\mu \mathrm{DIC}$ ) strain mapping determined this localised plasticity to occur in colonies where the lamellar orientation to the loading axis was close to $45^{\circ}$ [5]. Similarly, Wu et al. [7, 8] reported interlamellar microcracking upon sub-yield loading and showed that fatigue crack growth tended to occur in these regions.

The aim of this paper is to understand where deformation starts during monotonic loading of lamellar TiAl alloys. The effects of temperature and of lamellar thickness on the accumulation of sub-macro yield plasticity is addressed by the combination of nano-scale DIC (nDIC) strain mapping [9] and electron backscatter diffraction (EBSD) crystal orientation mapping of the pre- and post- general yielding monotonic tensile deformation behaviour of macroscopic polycrystalline testpieces of nearly lamellar 3 
commercial alloy $\mathrm{Ti}-45 \mathrm{Al}-2 \mathrm{Nb}-2 \mathrm{Mn}(\mathrm{at} \%)-0.8 \mathrm{vol} \% \mathrm{TiB}_{2}$ at both $25{ }^{\circ} \mathrm{C}$ and $700{ }^{\circ} \mathrm{C}$ for two conditions of lamellar thickness.

Elsewhere, preliminary results by the present authors have shown from DIC strain mapping of deformed micropillars of TiAl lamellar stacks milled from individual colonies that by $10 \%$ strain, bands of high shear strain develop near or at the lamellar interfaces [10]. Further, high temperature testing of micropillars is possible up to $630{ }^{\circ} \mathrm{C}$ ex situ [11], and using in situ equipment [12], up to $800{ }^{\circ} \mathrm{C}$ [13]. This macroscopic tensile testing is combined with microcompression of pillars of the same alloy in the softest lamellar orientations, using nDIC strain mapping by a method similar to [10], but at both $25^{\circ} \mathrm{C}$ and $700{ }^{\circ} \mathrm{C}$, and with loading to low strains, enabling the onset of plasticity to be studied.

\section{Experimental Procedures}

\subsection{Macro-tensile testing}

\subsubsection{Material and metallographic preparation}

The TiAl alloy, Ti-45Al-2Nb-2Mn(at\%)-0.8 vol\% $\mathrm{TiB}_{2}$ (Ti4522XD), was received as a centrifugal casting, which had been hot isostatically pressed at $1250 \pm 10{ }^{\circ} \mathrm{C}$ for $4 \mathrm{~h}$ at a pressure of $140 \mathrm{MPa}$ under an argon atmosphere and then vacuum heat treated at $1010^{\circ} \mathrm{C}$ for $8 \mathrm{~h}$, followed by furnace cooling to below $500{ }^{\circ} \mathrm{C}$. This yielded a nearly lamellar microstructure. The alloy composition measured using techniques specified by, and according to, ASTM standards [14-17] is given in Table 1. A more refined lamellar structure was produced by a heat treatment for two hours at $1350{ }^{\circ} \mathrm{C}$ in a furnace (Carbolite, Verder Scientific, Germany) and air cooling, with samples wrapped in Ta foil and encapsulated in quartz glass tubes in $0.3 \mathrm{~atm}$ Ar throughout. This was followed by a stabilisation treatment for eight hours at $850{ }^{\circ} \mathrm{C}$; besides air cooling, all thermal ramps were performed at $10{ }^{\circ} \mathrm{C} \mathrm{min}^{-1}$.

The microstructural parameters such as the colony size and the $\gamma$-TiAl and $\alpha_{2}-\mathrm{Ti}_{3} \mathrm{Al}$ lamellar thicknesses of the two material conditions were determined by backscatter and transmission Kikuchi diffraction (TKD) $[18,19]$, Table 2. Transmission samples were produced by first dimple grinding electro-discharge 
machined $3 \mathrm{~mm}$ diameter discs with a $1 \mu \mathrm{m}$ diamond suspension to just $20 \mu \mathrm{m}$ thick (Dimple Grinder

656, Gatan, USA) and then thinning until perforation in a twinjet electropolisher (Tenupol-5, Struers, Denmark) using a solution of 5\% perchloric acid, $35 \%$ butanol, $60 \%$ methanol by volume held at $32 \mathrm{~V}$ and $-30{ }^{\circ} \mathrm{C}$. TKD was carried out on a dual beam FIB/SEM (Helios NanoLab, FEI, USA) with an EBSD detector and acquisition software (NordlysNano, Oxford Instruments, UK) employing the refined accuracy routine [20] at $30 \mathrm{kV}, 6.4 \mathrm{nA},-20^{\circ}$ tilt, a working distance of $1.5 \mathrm{~mm}$ and a $20 \mathrm{~nm}$ stepsize.

Following electro-discharge machining, tensile specimens with a $1 \times 2 \times 2.5 \mathrm{~mm}^{3}$ gauge length, Fig. 1(a), were ground on all sides, with one large face prepared for electron backscatter diffraction (EBSD) mapping by vibratory polishing in a colloidal silica solution for $48 \mathrm{~h}$. EBSD mapping of the region of interest within the gauge length before mechanical testing was performed on the same dual beam FIB/SEM at $20 \mathrm{kV}, 6.4 \mathrm{nA}, 70^{\circ}$ tilt, a working distance of $10 \mathrm{~mm}$ and a $200 \mathrm{~nm}$ stepsize. The angle, $\Phi$, of the lamellar stacks of each colony to the loading axis required the appropriate $(111)_{\gamma}$ interfacial plane to be identified from the Euler angles, using Vesta [21].

\subsubsection{Mechanical testing}

Tensile testing was carried out ex situ on a $25 \mathrm{kN}$ screw machine (Tinius Olsen, UK) at a strain rate of $10^{-3} \mathrm{~s}^{-1}$, to $64 \%$ and then to $82 \%$ of the general yield stress for each material condition, and then to specimen failure. The yield stresses of each condition were determined beforehand $[22,23]$ on samples without strain mapping metrology. Samples were heated in air by a halogen lamp hoop heater (Heraeus Noblelight $\mathrm{GmbH}$, Germany), stable to $\pm 0.5{ }^{\circ} \mathrm{C}$ of the setpoint, placed around the gauge length, with a Ktype thermocouple junction held in contact with the back surface of the tensile testpiece gauge section by a leaf spring to avoid the specimen failing at the weld. The system was allowed to thermally equilibrate until the rate of drift was at least an order of magnitude below the strain-rate. The experimental setup did not allow the macroscopic strain of the tensile specimens to be measured on the samples by contact extensometry, so only stress against crosshead displacement curves were plotted. 


\subsubsection{Mapping of surface strain}

For mapping of surface strains by digital image correlation (DIC) at $25^{\circ} \mathrm{C}$ and $700{ }^{\circ} \mathrm{C}$, a remodelled $\mathrm{Au}$ speckle pattern was applied after EBSD mapping of the unstrained region of interest. A full description of the high temperature speckling method and characterisation of the pattern and its robustness is given elsewhere [9]. Samples were transferred, unloaded, from the test rig to the dual beam FIB/SEM where the speckle pattern was imaged in high contrast backscatter mode at $4000 \times$ magnification as a $9 \times 8$ array of $4096 \times 3536 \mathrm{px}^{2}$ images, which were stitched before analysis using the stitching plugin [24] in the Fiji [25] implementation of ImageJ [26], which employs linear interpolation for sub-pixel stitching and linear blending of intensities in the fusion region. Image correlation of pre- and post-deformation SEM images was performed on commercially available DIC software (DaVis, LaVision, Germany), with a subset size of $8 \times 8$ pixels and $25 \%$ overlap, which gave a strain mapping resolution of $63 \times 63 \mathrm{~nm}^{2}$ for as-HIPped samples tested at $700{ }^{\circ} \mathrm{C}$. Digital image correlation of repeatedly imaged regions before testing yielded a noise level in the maximum shear strain resulting from SEM scanning imperfections of $0.4 \pm 0.3 \%$ for this subset size. Throughout the current study, DIC strain maps are mapped onto the undeformed geometry [27].

\subsection{Microcompression testing}

\subsubsection{Material and metallographic preparation}

Cuboidal microcompression specimens $5 \times 5 \times 11 \mu^{3}$ in size were produced in single colonies of the same TiAl alloy by $\mathrm{Ga}^{+}$focussed ion beam (FIB) milling close to a sample edge, as per a method reported elsewhere [10]. The crystal orientations of the lamellae and their angle to the loading axis, $\Phi$, of the exposed side face of the pillars were determined by electron backscatter diffraction on the FIB/SEM, similarly to [10].

\subsubsection{Mechanical testing}

Mechanical testing was undertaken using a $10 \mu \mathrm{m}$ diamond punch (Synton, Switzerland) at $25^{\circ} \mathrm{C}$ and $700{ }^{\circ} \mathrm{C}$ on a SEM nanoindenter (Alemnis, Switzerland) $[12,28]$, which heats both the sample and compression tip independently. The micropillars were loaded at $0.05 \mu \mathrm{m} \mathrm{s}^{-1}$ (equivalent to a strain rate of 
$\sim 4 \times 10^{-3} \mathrm{~s}^{-1}$ ) to $0.5-2 \%$ plastic strain, followed by immediate unloading at the same rate. The

unloading was paused at $\sim 2 \mathrm{mN}$ and the load drift rate was measured to ensure that it was low. For compression testing, the sample and indentation tip heaters operated at constant power. The results from the compression of nine soft mode oriented pillars by this method are reported in the current study.

\subsubsection{Mapping of surface strain}

Surface strain mapping of the exposed pillar side face was achieved by digital image correlation (DIC) of SEM secondary electron images of the Pt speckle pattern electron beam-deposited following pre-test EBSD mapping, as in [10, 27]. DIC of pre- and post-deformation images was performed equivalently to [10] with a subset size of $16 \times 16$ pixels, giving a resolution of $108 \times 108 \mathrm{~nm}^{2}$, using a $25 \%$ overlap. The noise level for shear strain, determined as in section 2.1.3, was $0.6 \pm 0.3 \%$.

\subsubsection{TEM imaging of slip bands}

Following post-test SEM imaging of the speckle pattern on the pillar, and EBSD mapping, a Pt strap was deposited on the top and side faces of the pillars by e-beam gas injection system (GIS) deposition in the FIB/SEM. Ion beam Pt GIS deposition was then used to fill in the cavity on either side of the pillar to act as a support. A standard FIB liftout for transmission electron microscopy (TEM) could then be produced. Samples were FIB thinned to approximately $100 \mathrm{~nm}$ thick. Imaging was performed in scanning mode on a $200 \mathrm{kV}$ field emission gun TEM (Osiris, FEI, USA), using both bright field (STEM-BF) and high angle annular dark field (STEM-HAADF) detectors. All liftouts were oriented within the TEM such that the incoming e-beam lay parallel to the interlamellar $(111)_{\gamma}$ planes to minimise the imaged width of the lamellar interfaces.

\section{Results}

\subsection{Macroscale testing}

Tensile testing at room temperature of the as-received, thicker lamellar condition was performed to stresses of $350 \mathrm{MPa}$ and $450 \mathrm{MPa}$ and then to rupture at $590 \mathrm{MPa}$, as per the loading curves in Fig. 1(b). The above pre-yield loading steps corresponded to $64 \%$ and $82 \%$, respectively, of the $550 \mathrm{MPa}$ yield 
stress at $25{ }^{\circ} \mathrm{C}$ for the as-received condition. Approximate strains achieved during nominally elastic

loading, reported in Table 3, were calculated from the stresses applied, using temperature dependent literature values for the Young's modulus of each phase [29] and a rule of mixtures based on the volume fractions in Table 2.

Complete unloading between steps enabled SEM imaging of the applied Au surface speckle pattern. The region of interest in Fig. 2(a), with colony orientations extracted in Fig. 2(b), was hence mapped for surface strain after each loading step. Maps of the maximum shear stress are given following these load steps in Fig. 3(a,b). The total normal strain along the loading axis for the sample in Fig. 3 was calculated to be $0.16 \%$ by summing local axial strains across the DIC strain maps after the first loading step, then $0.18 \%$ after the second, see Table 3 . On the other hand, localised straining was measured, as arrowed and detailed in Fig. 3(a,b). Upon overlaying the network of colony boundaries, these narrow bands of localised plasticity were found within individual colonies, stretching part or full-way across them, but not propagating beyond the colony boundaries. All the colonies where such localised deformation was active in the thick lamellar condition were soft-mode oriented, with angles $35^{\circ}<\Phi<57^{\circ}$. Raising the load from $350 \mathrm{MPa}$ to $450 \mathrm{MPa}$ inccreased both the number of bands of shearing and the extent of shearing. In Fig. 4(a,b), lineplots of the shear strain along all the pre-yield localised deformation lines at both stress levels indicate that the maximum extent of shear is consistently within the bulk of the colony, with a distinct decrease in shear strain towards the colony edges.

\subsubsection{Location of plasticity}

By carefully overlaying the DIC strain map on the EBSD mapping and BSE imaging data, and using features such as boride particles as an invariant marker, the locations of the fine bands of localised plasticity generated at stresses below the general yield stress could be related to the lamellar microstructure. This is illustrated in Fig. 5(a) for the left hand colony in Fig. 3(b), which shows multiple pre-yield deformation lines; it is clear that such microplasticity operates parallel to the lamellar interfaces, longitudinally. Further, it occurs at the lamellar interfaces, be they $\gamma / \alpha_{2}$ interphases, or $\gamma / \gamma$ 
twin, pseudo-twin or order variant type. Unfortunately, there was an insufficient population of bands of

localised plasticity that occurred below the general yield stress in the region of the sample ( 8 bands measured across $230 \times 200 \mu \mathrm{m}^{2}$ area) for meaningful statistics on the proportions of lamellar interface types involved to be extracted.

\subsubsection{Effect of temperature}

Samples tested at $700{ }^{\circ} \mathrm{C}$ were first loaded to $64 \%$, then to $82 \%$ of the general yield stress of $400 \mathrm{MPa}$, that is $255 \mathrm{MPa}$ and $327 \mathrm{MPa}$, Fig. 1(b). The noise in DIC strain maps, Fig. 6(a), after unloading was less uniform for testing at $700{ }^{\circ} \mathrm{C}$ than at $25^{\circ} \mathrm{C}$; this is seen in particular by the increased local shear strain noise on the $\alpha_{2}-\mathrm{Ti}_{3} \mathrm{Al}$ lamellae. Nevertheless, the magnitude of strain within the narrow bands of localised plasticity is much higher, reaching $\sim 8 \%$ locally for normal strain along the loading axis, as in the detail in Fig. 6(b). However, after loading to $327 \mathrm{MPa}$, only a single narrow band of localised deformation was observed at $700{ }^{\circ} \mathrm{C}$, despite similar levels of elastic strain being achieved at $700{ }^{\circ} \mathrm{C}$, as those at $25{ }^{\circ} \mathrm{C}$, based on the calculations for Table 3. The localised deformation here, extracted in Fig. 4(d) and 5(b), was longitudinal and occurred along a lamellar interface in a soft-mode colony, similarly to deformation identified at $25^{\circ} \mathrm{C}$ in section 3.1.1.

\subsubsection{Effect of lamellar refinement}

The refined lamellar condition was tested at both $25{ }^{\circ} \mathrm{C}$ and $700{ }^{\circ} \mathrm{C}$ to the same proportions of the respective general yield stresses as for the thicker lamellar condition, Fig. 1(b). The DIC strain maps are given in Fig. 7(a-e)

After loading to each successive stress step, a greater number of bands localised of plasticity are measured in the refined lamellar condition, at both temperatures, than in the thick lamellar condition, Fig. 7(a-d), particularly below the general yield stress at room temperature. This is summarised in the histogram, Fig. 8(a). Further, such localised plasticity operates with the same longitudinal morphology as the previous microstructural condition, Fig. 3(a,b), and occurs in soft-mode oriented lamellar colonies. However, as illustrated in Fig. 2(f,h), the resolution of the EBSD maps was insufficient to resolve the 
refined lamellae such that the positions of the localised plasticity could not be accurately determined

relative to the lamellar interfaces. As for the thicker lamellar condition, hard-mode oriented colonies of the refined lamellar condition remain undeformed below the general yield stress.

\subsubsection{Plastic flow at applied stresses above the general yield stress}

All the tensile testpieces were further loaded to failure, as per the loading curves in Fig. 1(b). All samples failed in the gauge section, several hundreds of microns away from the regions of interest for DIC strain mapping. The strain maps for the same regions of interest in Fig. 2 are given in Fig. 3(c), 6(c) and 7(e). In all cases, significant heterogeneities in the distribution of plasticity are observed, with soft-mode colonies deforming by the operation of several tens of discrete longitudinal bands of localised plasticity per colony. There was a high variability in the spacing of such longitudinal plasticity, ranging from only a few hundred nanometres to tens of microns within a same colony, Fig. 6(c). In contrast, hard mode colonies showed either no measurable plasticity, or a few longitudinal bands and small amounts of transverse plasticity, fairly diffusely spread throughout colonies and, for the most part, undergoing shear strains approximately ten times lower than those for longitudinal motion. At $700{ }^{\circ} \mathrm{C}$, both an increased number of bands of localised plasticity (see Fig. 8) and a higher macroscopic uniaxial strain (1.57\% at $700{ }^{\circ} \mathrm{C}$ vs. $0.69 \%$ at $25^{\circ} \mathrm{C}$ for as-received condition, Table 3 ) occurred at fracture, compared to at $25^{\circ} \mathrm{C}$.

The bands of localised plasticity occurring upon loading below the general yield stress in the as-received condition were consistently not the bands with the highest shear strain at specimen failure. That is to say, many other bands of localised plasticity develop before specimen failure, both in colonies where such bands were identified below the general yield stress, and in colonies where they were not; some of these bands that form at higher stresses produce higher local shear strains at specimen failure than all those that initiated below the general yield stress, as arrowed in Fig. 3(c) and 6(c), and extracted as lineplots in Fig. 4. In contrast, this was not the case for the air-cooled condition tested at $700{ }^{\circ} \mathrm{C}$ : the bands of localised plasticity that initiated below the general yield stress produced the highest local shear strain at specimen failure, Fig. 7(e). Furthermore, from the histogram in Fig. 8(b) that counts all bands of 
localised plasticity at specimen failure, $3-4$ times more longitudinal slip lines occur at specimen failure

in the as-received condition than in the air-cooled conditions, at both $25{ }^{\circ} \mathrm{C}$ and $700{ }^{\circ} \mathrm{C}$.

Strain transfer between colonies was observed to operate by several different mechanisms. Direct strain transfer, commonplace in fcc metals [30]; at $700{ }^{\circ} \mathrm{C}$, it was rare and was only identified for the asreceived condition, between longitudinal colonies where the angle between the lamellar planes either side of the boundary was low, as in Fig. 9(a,b). At room temperature, this mechanism was supplemented by direct strain transfer from longitudinal mode deformation in a first colony onto deformation systems operating transversally to the lamellar planes in a second, Fig. 9(c); this occurred when the two colonies were highly misoriented with regards to their lamellar planes. From the DIC strain maps alone it is not possible to determine whether such transverse deformation was by a slip or a twinning mechanism. At $700{ }^{\circ} \mathrm{C}$, an alternative strain transfer mechanism was operative in the case of highly misoriented neighbouring colonies. Instead, transfer could be ensured by variable extents of slip on systems operating nearly perpendicular to the incoming shear direction, resulting in regions of local lattice rotation ahead of the colony boundary and extending, in some cases, several tens of microns into the receiving colony, Fig. $9(\mathrm{~d}-\mathrm{f})$. These features can be specifically resolved from the DIC strain map, as highlighted in Fig. 6(c) and resolved in Fig. 9(f). This latter strain transfer mechanism has been characterised extensively by the authors in a recent publication [31].

Electron imaging of the regions of interest after fracture revealed cracking of colony boundaries, Fig. 9(g), particularly at high misorientation boundaries in cases where the above strain transfer mechanisms had not been operational. This was confirmed by measuring the rotation of the lattice using DIC in Fig. 9(h), where $\sim 2^{\circ}$ clockwise (counter-clockwise) rotation is observed on the left (right) below the lenticularly opening crack that extends perpendicular to the loading direction.

\subsection{Microscale testing}

Further, the resolution of the large area EBSD maps in both material conditions was insufficient to determine whether the onset of plasticity occurred at, or nearby to, the lamellar interfaces. Hence, 
microcompression testing was undertaken with the aim of determining where these longitudinal bands of

localised plasticity formed in soft-mode oriented colonies. The lamellar structure was now mapped for its crystal orientations on the side face of the pillars with a $40 \mathrm{~nm}$ stepsize, compared with $200 \mathrm{~nm}$ for the tensile specimens. Pillars were loaded to just beyond yielding, Fig. 10, at both $25{ }^{\circ} \mathrm{C}$ and $700{ }^{\circ} \mathrm{C}$ to imitate the loading conditions experienced by the softest colonies when the tensile testpieces were loaded below the macroscopic yield point.

\subsubsection{Onset of plastic flow}

The combination of DIC strain mapping, EBSD orientation mapping before and after compression, and post mortem TEM enabled both the location of the initial localised plasticity relative to the lamellae, and its nature, that is either twinning, slip or interfacial sliding, to be determined. This combination of information is illustrated in Fig. 11(a - f) and Fig. 12(a,b) for a pillar tested at room temperature. A summary of the remainder of the pillars tested at the same temperature is given in Fig. $11(\mathrm{~g}-\mathrm{r})$.

At room temperature, the onset of plasticity always occurred near lamellar boundaries, Fig. 11, and of the five boundary types, most commonly (64\%) near the $\gamma / \alpha_{2}$ interphase. The lines of localised plasticity measured by DIC were parallel to the lamellae in all cases; the extent of strain along the lines is not necessarily uniform: often the shear strain is highest where the band intersects the pillar edge and decreases towards the pillar centre. Only a small number, generally three or less, such deformation lines developed in each pillar. This initial plasticity could be located throughout the height of the pillars; that is to say, initial plasticity did not consistently locate in the top or base of the pillar where the stress state is thought [32] to be least uniaxial due to the local constraint of the punch or of the supporting material below the pillar.

STEM-BF and HAADF imaging, Fig. 12, further found such localised plasticity to occur in the $\gamma$-TiAl phase and, again, most often at $\gamma / \alpha_{2}$ interphase boundaries. The deformation mechanism was either longitudinal twinning, which was identified by the morphology of the deflected pillar edges [33], where one face of the twin consistently contacted a lamellar interface, or longitudinal slip, where the slip lines 
generally lay $30-50 \mathrm{~nm}$ from the $\gamma / \alpha_{2}$ or $\gamma / \gamma$ interfaces. No occurrences of sliding of the lamellar interfaces were identified.

In most cases, the longitudinal deformation lines due to slip were found on the STEM images to do so by dislocation glide on a single plane; occasionally, several slip lines on either side of a $\gamma / \gamma$ interface, as in Fig. 12(c,d), were observed to constitute a single deformation line in the strain maps. However, further deformation structures were identified by TEM imaging that were not apparent on the DIC strain maps. Indeed, the occurrence of transverse twinning is evident throughout the height of pillars 3 and 4, Fig. 12(c-f), but not in 1 and 5, Fig. 12(a,b,g,h). It may be that the width of transverse twins is too small relative to the resolution of the strain maps. To gain a quantitative measure of the balance of the axial strain $\varepsilon_{\mathrm{yy}}$ between the longitudinal lines of localised plasticity and the finer-scale deformation of the remainder of the pillars, masking functions in the DaVis software were employed to determine the average axials strains of these two regions. The value, $P$, was defined as the proportion of the axial compression of the pillar that is generated in the localised plasticity bands on the DIC maps, according to:

$$
P=\frac{\varepsilon_{\mathrm{yy}, \mathrm{band}} A_{\mathrm{band}}}{\varepsilon_{\mathrm{yy} \text {,avg }}\left(A_{\mathrm{ext}}+A_{\mathrm{band}}\right)}
$$

where $A_{\ldots .}$ is the area of a region, and the subscripts 'band' and 'ext' refer to the regions containing, and not containing, respectively, the longitudinal lines of intense plasticity. The results of the measurements and calculations are given in Table 4 . It should be noted that the base noise level in $\varepsilon_{\mathrm{yy}}$ from recorrelation of a repeatedly imaged region, as in section 2.2 .3 , is $0.044 \%$, such that the average strains measured in almost all regions lie above this noise threshold. For pillars compressed at $25{ }^{\circ} \mathrm{C}$, the range of values for $P$ is wide (25.2\% to $94.4 \%) . \varepsilon_{\mathrm{yy}}$ is approximately one order of magnitude higher in the bands, $\varepsilon_{\mathrm{yy}, \text { band }}$, than in the remainders of the pillars, $\varepsilon_{\text {yy,ext }}$. However, when the axial displacement (rather than strain) is considered, in $P$, two groups emerge: those where the longitudinal bands dominate deformation, \#1 and 5, which contained almost no transverse twins, and correspondingly carry the highest $P$ (both above 90 
$\%$ ), and secondly those where $P$ is closer to $50 \%$. In the latter, pillars 2,3 and 4 , longitudinal

1

deformation mechanisms carry approximately the same proportion of the axial compression as the remaining transverse systems. In fact, in \#4, the remainder region of the pillar produces a higher axial compression than the longitudinal bands of localised plasticity $(P=25.2 \%)$. There is no correlation between $P$ and the average axial strain achieved in the full pillar, $\varepsilon_{\mathrm{yy}, \mathrm{avg}}$, see Table 4 .

At the top of pillars, where they are laterally constrained by the punch, a fine array of longitudinal slip lines and transverse twins was observed by STEM imaging to develop in most pillars, Fig. 12.

\subsubsection{Effect of temperature}

DIC strain mapping and EBSD of the pillars tested at $700{ }^{\circ} \mathrm{C}$ indicated the same patterns of initial localised deformation as at room temperature, Fig. 13. STEM imaging, Fig. 14, similarly revealed longitudinal deformation at lamellar interfaces (particularly $\gamma / \alpha_{2}$ type, $77 \%$ ) to be associated with longitudinal twinning in contact with the interface, and slip lines within a few tens of microns of the interface. The occurrence of multiple, closely spaced slip lines, which formed a single deformation line on the DIC strain maps, was common at $700^{\circ} \mathrm{C}$.

As at room temperature, some pillars compressed at $700{ }^{\circ} \mathrm{C}$ displayed extensive amounts of transverse twinning that is not evident from the DIC maps. However, there is no substantial variation in the extent of transverse twinning between test temperatures, though this may be due to the limited number of testpieces. Some pillars display almost no transverse twins (1, 5, 7 and 8$)$, whilst others are highly populated with them (4 and 6). Again, the distribution of strain between longitudinal mechanisms and the remainder of the pillar was calculated, Table 4. A much lesser spread in the $P$ value identified in section 3.2.1, was observed than at $25^{\circ} \mathrm{C}$. Relative to the two classes identified in section 3.2.1, all pillars are in the class with $P$ close to $50 \%$, whether or not transverse twins exist. Again, $P$ did not correlate with $\varepsilon_{y y, a v g}$. 


\section{Discussion}

\subsection{Location of plasticity occurring below the general yield stress}

The present method for measuring the occurrence of localised plasticity below the general yield stress benefits from the use of a well-adhered overlay speckle pattern [9], which unlike alternatively used subtractive patterning techniques such as etching $[5,34]$ does not cause preferential weakening of certain microstructural features such as grain boundaries. Hence one may be sure that initial plasticity locating near lamellar interfaces is not simply a result of the experimental method, but rather a genuine characteristic of the TiAl alloy. Further, whereas TEM imaging of dislocation structures has previously been employed to demonstrate plasticity below the general yield stress in TiAl [5], the $63 \times 63 \mathrm{~nm}^{2}$ resolution of the DIC used here enabled not only more precise localisation of strain than previously achieved by DIC on TiAl [5, 35-37], but also the magnitude of the strain from slip to be determined. This information is crucial in differentiating between regions of relatively little dislocation motion and others where there has been extensive dislocation glide; this may not be evident from a single post-mortem TEM image. The present combination of techniques is therefore a powerful tool for locating and characterising even low levels of plasticity that may occur before the onset of general yielding.

It is encouraging that in-so-far as the resolution of the DIC strain and EBSD maps indicate, the basic location of initial plasticity is identical in both the polycrystalline tensile testpieces and the single colony microcompression specimens at $25{ }^{\circ} \mathrm{C}$ and $700{ }^{\circ} \mathrm{C}$. Recent comparison of $\mathrm{Ga}^{+}$and $\mathrm{Xe}^{+}$milling methods [38] has revealed significant Ga build-up along crystal boundaries which may modify the mechanical properties of the interface region, and results in a reduced strength. However, the high coherency of the lamellar interfaces in $\gamma$-TiAl alloys relative to higher angle grain boundaries is likely to render the $\gamma / \gamma$ and $\gamma / \alpha_{2}$ lamellar interfaces less susceptible to Ga segregation. Although microplasticity in the pillars was most common in the vicinity of interphase boundaries, the initial localised plasticity was also found to locate near the $\gamma / \gamma$ lamellar interfaces in all conditions. It is well known that the top and bottom of micropillars experience stress concentration effects as a result of constraint by the punch or the base [32]; however, in the micropillars here, the localised plasticity often occurred outside of these regions, such 
that the shear stress on the operative deformation systems can only have been raised relative to the

externally applied load by the presence of lamellar interfaces. The experimental evidence suggesting the existence of stress concentration effects induced by lamellar interfaces is consistent with first principles studies [39-41] which have determined the TiAl lamellar interfaces to be both high energy sites and stress concentrators; this effect was calculated to be highest for the $\gamma / \gamma$ pseudo-twin interface and the $\gamma / \alpha_{2}$ interphase boundary.

The localised plasticity occurring below the general yield stress in the present study is not due to stress concentrators such as hard particles [42] and cracks [35]. Instead, this plasticity is a result of the lamellar structure. This relationship is two-fold: it is well reported [2,3] that the lamellar orientation to the loading axis strongly affects the yield stress due to Hall-Petch strengthening of the transverse slip systems [43] by the lamellar interfaces. As longitudinal mechanisms are favoured over transverse ones down to even quite low Schmid factors, as seen in Fig. 6(c) where slip parallel to the lamellae is favoured even in colonies where $\Phi$ is as low as $14^{\circ}$ and as high as $73^{\circ}$, an up to 4 -fold variation exists in the applied uniaxial stress to yield a TiAl lamellar stack, dependent on its orientation to the loading axis [2]. It is evident that the plastic anisotropy is greater than in fcc metals, and even for hexagonal close-packed (hcp) structures, if both slip and deformation twinning is considered, this variability is unusually high [44-46]. As a result, when the general yield stress for a polycrystal of lamellar TiAl colonies is reached, many of the softest colonies are already loaded above their respective uniaxial yield stresses.

The second aspect of the relationship between microplasticity and the lamellar structure is that the lamellar interfaces act as extended two-dimensional stress concentrators. The effect of $\Sigma 3$ twin interfaces in a Ni superalloy on generating sub-yield plasticity parallel and $\sim 100 \mathrm{~nm}$ from such interfaces has been attributed to differences across the boundary in the elasticity tensor in the direction of the loading axis [47]. In the fully ordered structure of TiAl, the lamellar interfaces are elastically strained by both hcp-fct (face-centred tetragonal) and fct-fct lattice mismatches across the boundary. It is unclear whether it is the differences in elastic modulus or the lattice misfit strains that are the predominant factor contributing to stress concentration near the lamellar interface. Nevertheless, when compared to equiaxed grained 
$\gamma$-TiAl, the existence of lamellar interfaces means that the applied stress to activate slip is lower in the

lamellar structure for the softest orientation, as a result of this stress concentration as such lamellar interfaces don't exist in equiaxed $\gamma$-TiAl grains (only a few, occasional, true twin interfaces exist in equiaxed grained $\gamma$-TiAl [48]). This dependence of the incidence of localised plasticity below the general yield stress on the morphology of the $\gamma$-TiAl phase has been confirmed at room temperature in another study [5] where such microplasticity was not detected in a duplex microstructure of $\mathrm{Ti}-44 \mathrm{Al}-8 \mathrm{Nb}-1 \mathrm{~B}$ (at.\%), whereas it was in the case of nearly and fully lamellar structures of the same alloy for a same externally applied stress. However, in that study, the localised plasticity was reported to be due to microcracking below the general yield stress, based on acoustic emissions, SEM imaging and AFM measurements of $\sim 10 \mathrm{~nm}$ high interlamellar ledges in the middle of colonies [6]. Further, another study in which Ti4522XD was loaded in tension below the general yield stress at $700{ }^{\circ} \mathrm{C}$ [49] reported the formation of interlamellar ledges, i.e. sliding at the lamellar interfaces, based on in-situ BSE imaging. Instead, here, at both $25^{\circ} \mathrm{C}$ and $700{ }^{\circ} \mathrm{C}$, such localised plasticity, identified in microcompression samples by a combination of DIC and TEM, was attributed to longitudinal slip occurring $30-50 \mathrm{~nm}$ away from lamellar interfaces, and longitudinal twinning propagating from the interfaces, without cracking. These two latter deformation mechanisms maintain material cohesion and may produce equivalent surface steps as previously identified by AFM [6], have the same appearance in BSE imaging as the features reported to be microcracks and interfacial sliding [50], and, furthermore, microplasticity may generate acoustic emissions [51], similarly to microcracking, as remarked by Appel et al. [46].

The characterisation of the strain distribution between the few longitudinal deformation lines and the remainder of the pillar bulks revealed that the axial compression is relatively equally divided between the intense localised longitudinal plasticity and the remaining volumes that underwent transverse mode deformation, for soft mode oriented pillars compressed at $700{ }^{\circ} \mathrm{C}$. In contrast, pillars compressed at $25^{\circ} \mathrm{C}$ had a more variable distribution of the axial displacement between the longitudinal and transverse mechanisms; in some, the plasticity of the transversely slipping and twinning volumes generated less than one tenth of the total compression. This is consistent with the increased ease of operating 17 
unconstrained longitudinal twinning in the $\gamma$-TiAl phase at $25^{\circ} \mathrm{C}$ relative to $700{ }^{\circ} \mathrm{C}[52,53]$, whereas the

occurrence of constrained transverse twinning is generally lower at lower temperatures, such that a greater imbalance in the operation of the two twin modes should exist at $25^{\circ} \mathrm{C}$ than at $700{ }^{\circ} \mathrm{C}$.

\subsection{Impact of sub-yield plasticity}

In common engineering materials cycled at threshold conditions, in the absence of classical stress concentrators, the flow stress of the bulk of each grain is not normally exceeded, whereas in TiAl alloys this is not the case for all lamellar colonies. Indeed, in high cycle fatigue (HCF), the run-out stress $\left(10^{7}\right.$ cycles without failure) for TiAl alloys remains at $\sim 0.8$ UTS up to $700{ }^{\circ} \mathrm{C}[54]$, and a common design threshold for operation of aero-engine parts is $50 \%$ of this stress [55]. Hence, it is feasible for colonies to be loaded in service, at $25{ }^{\circ} \mathrm{C}$, to $0.5 \times 0.8 \times \sigma_{\mathrm{y}}=220 \mathrm{MPa}$ for the as-HIPped Ti4522XD condition. Therefore, even at this conservative design threshold, in the most preferentially oriented colonies where the Schmid factor for longitudinal deformation mechanisms is close to 0.5 , the critical resolved shear stress for activation of slip or twinning may be exceeded, e.g. $\tau_{\mathrm{CRSS}}=100 \mathrm{MPa}$ for longitudinal twinning of $\gamma$-TiAl [10]. This event may occur fully within the bulk of a lamellar colony, far from stress concentrators such as grain boundaries and hard particles. Furthermore, as cycling progresses beyond the first loading cycle investigated here, both the strain generated in a given localised plasticity band, and the number of active localised plasticity bands may increase.

The effect of localised plasticity on the fatigue life of TiAl components has been studied by Wu et al. [8] at room temperature by pre-loading samples to $95 \%$ of the general yield stress. This causes a reduction in the fatigue life at a given stress relative to non-pre-loaded material. Oxidation tinting at $700{ }^{\circ} \mathrm{C}$ associated cracks formed during pre-loading with the final failure. Interlamellar crack formation was attributed to poor strain transfer between highly misoriented soft-mode colony pairs as they intersected the surface. At highly misoriented colony boundaries in the present study, strain transfer can in fact occur by the formation of regions of local lattice rotation, in which the strains are accommodated by local lattice curvature. 
Stinville et al. were able to associate slip bands that formed near twin interfaces in René 88DT superalloy

below the general yield stress with eventual fatigue crack formation at room temperature [47]; furthermore, such microslip bands were also found to be the ones on which the greatest strains occurred after yielding [34]. However, in the TiAl studied here in the as-HIPped condition, the initial slip bands did not cause the greatest strain after yielding, regardless of temperature. This suggests that for TiAl in the as-HIPped condition, tracking the localised plasticity generated in a single loading cycle below the general yield stress may not in fact aid in locating the eventual site of fatigue cracking. However, where the lamellae were refined, many more slip bands formed below the general yield stress. It would appear that the formation of longitudinal localised plasticity almost exclusively in the vicinity of lamellar interfaces, and the ten-fold increase in the number of lamellar interfaces, are associated with the increased incidence of bands of localised plasticity in the refined condition below the general yield stress. However, beyond the yield stress, many more localised plasticity bands developed in the thicker lamellae material, Fig. 8(a,b), whereas in the refined condition, the bands nucleated below the general yield stress increase the magnitude of the shear strains in the bands with increasing load instead. The Cottrell crack nucleation mechanism [56] is known to operate in semi-brittle materials as dislocations pile-up against sessile locks located at the intersection of slip bands. A material where the same slip bands have higher shear strains, as in the refined lamellae condition here, may therefore be more susceptible to Cottrell-type flaw formation than a material where many more slip bands develop during loading, with each band operating to lower shear strains. This may be the reason for the lower (plastic) strain-to-failure of the refined lamellae material, $0.15 \%$, compared with the thicker lamellae, $1.57 \%$, at $700{ }^{\circ} \mathrm{C}$, see Table 3 .

With regards to fatigue crack growth (FCG), avoiding microcrack formation is essential, as these coalesce ahead of the primary crack in titanium aluminides and hence ensure crack growth [57]. Therefore it is expected that due to the Cottrell crack nucleation mechanism, the extensive localised slip occurring below the general yield stress in the refined lamellae microstructure even after a single loading cycle will aggravate FCG. 
In the tensile tests, localised plasticity below the general yield stress was less common at $700{ }^{\circ} \mathrm{C}$ than at

room temperature for the as-HIPped material, by almost an order of magnitude in both the number of localised plasticity bands and the shear strain generated per band. Combined with the result in [8] that localised plasticity below the yield stress weakens lamellar $\gamma$-TiAl alloys with regards to HCF, the strain distribution measured here, albeit on a single loading cycle, suggests that localised plasticity is more of a concern for the $\mathrm{HCF}$ of lamellar TiAl alloys at $25^{\circ} \mathrm{C}$ than at $700{ }^{\circ} \mathrm{C}$.

\section{Conclusions}

Macroscopic tensile testing in the nominally elastic regime, and microcompression testing to low plastic strains, of a polycrystalline nearly lamellar $\gamma$-TiAl alloy at both $25{ }^{\circ} \mathrm{C}$ and $700{ }^{\circ} \mathrm{C}$, has shown that localised slip and twinning can form at stresses well below the general yield stress. Combined with EBSD mapping and STEM imaging of the lamellae, this slip was found to occur exclusively in soft mode colonies and was located consistently in the $\gamma$-TiAl phase $\sim 30-50 \mathrm{~nm}$ away from, but not on, the lamellar interfaces. Such colonies were effectively loaded above their individual yield stress; further stress concentration by misfit strains and the mismatch of elastic moduli at the lamellar interfaces may also assist the development of localised plasticity below the general yield stress. Unlike previous reports, interlamellar cracking below the general yield stress, or sliding at the lamellar interfaces, were not observed.

This study has demonstrated that the highly localised plasticity that must precede failure in high cycle fatigue is inherently related to the lamellar structure of $\gamma$-TiAl alloys, which predetermines the locations of plastic strain accumulation, even in a single loading cycle. Further study is required to assess the impact of such pre-yield plasticity on the eventual fatigue cracking of cyclically loaded lamellar $\gamma$-TiAl alloys, in order to engineer more damage-tolerant TiAl alloy microstructures. 


\section{Acknowledgements}

1

2 3 4 6 7

The work was supported by the EPSRC / Rolls-Royce Strategic Partnership (EP/M005607/1). T.E.J.E. also acknowledges the kind support of the Worshipful Company of Armourers and Brasiers' Gauntlet Trust. 


\section{References}

[1] J. Larsen, A. Rosenberger, B. Worth, K. Li, D. Maxwell, W. Porter, Assuring reliability of gamma titanium aluminides in long-term service, Minerals, Metals and Materials Society/AIME, Gamma Titanium Aluminides 1999(USA) (1999) 463-472.

[2] T. Fujiwara, A. Nakamura, M. Hosomi, S.R. Nishitani, Y. Shirai, M. Yamaguchi, Deformation of polysynthetically twinned crystals of TiAl with a nearly stoichiometric composition, Philosophical Magazine A 61(4) (1990) 591-606.

[3] H. Inui, M.H. Oh, A. Nakamura, M. Yamaguchi, Room-temperature tensile deformation of polysynthetically twinned (PST) crystals of TiAl, Acta Metallurgica et Materialia 40(11) (1992) 30953104.

[4] K. Kishida, H. Inui, M. Yamaguchi, Deformation of PST crystals of a TiAl/Ti3Al two-phase alloy at $1000^{\circ} \mathrm{C}$, Intermetallics 7(10) (1999) 1131-1139.

[5] H. Jiang, F.A. Garcia-Pastor, D. Hu, X. Wu, M.H. Loretto, M. Preuss, P.J. Withers, Characterization of microplasticity in TiAl-based alloys, Acta Materialia 57(5) (2009) 1357-1366.

[6] D. Hu, A. Huang, H. Jiang, N. Mota-Solis, X. Wu, Pre-yielding and pre-yield cracking in TiAl-based alloys, Intermetallics 14(1) (2006) 82-90.

[7] R. Botten, X. Wu, D. Hu, M.H. Loretto, The significance of acoustic emission during stressing of TiAl-based alloys. Part I: Detection of cracking during loading up in tension, Acta Materialia 49(10) (2001) 1687-1691.

[8] X. Wu, D. Hu, R. Botten, M.H. Loretto, The significance of acoustic emission during stressing of TiAl-based alloys. Part II: Influence of cracks induced by pre-stressing on the fatigue life, Acta Materialia 49(10) (2001) 1693-1699.

[9] T.E.J. Edwards, F. Di Gioacchino, H.P. Springbett, R.A. Oliver, W.J. Clegg, Stable speckle patterns for nano-scale strain mapping up to $700{ }^{\circ} \mathrm{C}$, Experimental Mechanics 57 (2017) 1289-1309.

[10] T.E.J. Edwards, F. Di Gioacchino, R. Muñoz-Moreno, W.J. Clegg, Deformation of lamellar TiAl alloys by longitudinal twinning, Scripta Materialia 118 (2016) 46-50.

[11] S. Korte, R.J. Stearn, J.M. Wheeler, W.J. Clegg, High temperature microcompression and nanoindentation in vacuum, Journal of Materials Research 27(01) (2012) 167-176.

[12] J.M. Wheeler, J. Michler, Elevated temperature, nano-mechanical testing in situ in the scanning electron microscope, Review of Scientific Instruments 84(4) (2013) 045103.

[13] J.M. Wheeler, D.E.J. Armstrong, W. Heinz, R. Schwaiger, High temperature nanoindentation: The state of the art and future challenges, Current Opinion in Solid State and Materials Science 19(6) (2015) 354-366.

[14] Standard test method for determination of carbon in refractory and reactive metals and their alloys by combustion analysis, ASTM International, 2016.

[15] Standard test method for determination of hydrogen in titanium and titanium alloys by inert gas fusion thermal conductivity/infrared detection method, ASTM International, 2016.

[16] Standard test method for analysis of titanium and titanium alloys by direct current plasma and inductively coupled plasma atomic emission spectrometry (performance-based test methodology), ASTM International, 2013.

[17] Standard test method for determination of oxygen and nitrogen in titanium and titanium alloys by inert gas fusion, ASTM International, 2013. 
[18] R.R. Keller, R.H. Geiss, Transmission EBSD from $10 \mathrm{~nm}$ domains in a scanning electron microscope, Journal of Microscopy 245(3) (2012) 245-251.

[19] P.W. Trimby, Orientation mapping of nanostructured materials using transmission Kikuchi diffraction in the scanning electron microscope, Ultramicroscopy 120(0) (2012) 16-24.

[20] K. Thomsen, N.H. Schmidt, A. Bewick, K. Larsen, J. Goulden, Improving the accuracy of orientation measurements using EBSD, Microscopy and Microanalysis 19(SupplementS2) (2013) 724 725.

[21] K. Momma, F. Izumi, VESTA 3 for three-dimensional visualization of crystal, volumetric and morphology data, Journal of Applied Crystallography 44(6) (2011) 1272-1276.

[22] N. Martin, Rolls-Royce plc, private communication, 2015.

[23] Y.-W. Kim, S.-L. Kim, Advances in Gammalloy Materials-Processes-Application Technology: Successes, Dilemmas, and Future, JOM 70(4) (2018) 553-560.

[24] S. Preibisch, S. Saalfeld, P. Tomancak, Globally optimal stitching of tiled 3D microscopic image acquisitions, Bioinformatics 25(11) (2009) 1463-1465.

[25] J. Schindelin, I. Arganda-Carreras, E. Frise, V. Kaynig, M. Longair, T. Pietzsch, S. Preibisch, C. Rueden, S. Saalfeld, B. Schmid, J.-Y. Tinevez, D.J. White, V. Hartenstein, K. Eliceiri, P. Tomancak, A. Cardona, Fiji: an open-source platform for biological-image analysis, Nat Meth 9(7) (2012) 676-682.

[26] C.A. Schneider, W.S. Rasband, K.W. Eliceiri, NIH Image to ImageJ: 25 years of image analysis, Nat Meth 9(7) (2012) 671-675.

[27] F. Di Gioacchino, W.J. Clegg, Mapping deformation in small-scale testing, Acta Materialia 78 (2014) 103-113.

[28] J.M. Wheeler, P. Brodard, J. Michler, Elevated temperature, in situ indentation with calibrated contact temperatures, Philosophical Magazine 92(25-27) (2012) 3128-3141.

[29] R. Schafrik, Dynamic elastic moduli of the titanium aluminides, MTA 8(6) (1977) 1003-1006.

[30] F. Di Gioacchino, J. Quinta da Fonseca, An experimental study of the polycrystalline plasticity of austenitic stainless steel, International Journal of Plasticity 74 (2015) 92-109.

[31] F. Di Gioacchino, T.E.J. Edwards, G.N. Wells, W.J. Clegg, A new mechanism of strain transfer in polycrystals, Nature Communications, in review (2018).

[32] P.A. Shade, R. Wheeler, Y.S. Choi, M.D. Uchic, D.M. Dimiduk, H.L. Fraser, A combined experimental and simulation study to examine lateral constraint effects on microcompression of singleslip oriented single crystals, Acta Materialia 57(15) (2009) 4580-4587.

[33] A.J. Palomares-García, M.T. Pérez-Prado, J.M. Molina-Aldareguia, Effect of lamellar orientation on the strength and operating deformation mechanisms of fully lamellar TiAl alloys determined by micropillar compression, Acta Materialia 123 (2017) 102-114.

[34] J.C. Stinville, N. Vanderesse, F. Bridier, P. Bocher, T.M. Pollock, High resolution mapping of strain localization near twin boundaries in a nickel-based superalloy, Acta Materialia 98 (2015) 29-42.

[35] T. Niendorf, C. Burs, D. Canadinc, H.J. Maier, Early detection of crack initiation sites in TiAl alloys during low-cycle fatigue at high temperatures utilizing digital image correlation, International journal of materials research 100(4) (2009) 603-608.

[36] B. Bode, W. Wessel, A. Brueckner-Foit, J. Mildner, M. Wollenhaupt, T. Baumert, Local deformation at micro-notches and crack initiation in an intermetallic $\gamma$-TiAl-alloy, Fatigue \& Fracture of Engineering Materials \& Structures 39(2) (2016) 227-237. 
[37] C. Içöz, L. Patriarca, M. Filippini, S. Beretta, Strain accumulation in TiAl intermetallics via highresolution digital image correlation (DIC), Procedia Engineering 74(0) (2014) 443-448.

[38] Y. Xiao, J. Wehrs, H. Ma, T. Al-Samman, S. Korte-Kerzel, M. Göken, J. Michler, R. Spolenak, J.M. Wheeler, Investigation of the deformation behavior of aluminum micropillars produced by focused ion beam machining using Ga and Xe ions, Scripta Materialia 127 (2017) 191-194.

[39] M.H. Yoo, C.L. Fu, Physical constants, deformation twinning, and microcracking of titanium aluminides, Metall and Mat Trans A 29(1) (1998) 49-63.

[40] P.M. Hazzledine, Coherency and loss of coherency in lamellar Ti $\square \mathrm{Al}$, Intermetallics 6(7) (1998) 673-677.

[41] C.L. Fu, J. Zou, M.H. Yoo, Elastic constants and planar fault energies of Ti3Al, and interfacial energies at the Ti3AlTiAl interface by first-principles calculations, Scripta Metallurgica et Materialia 33(6) (1995) 885-891.

[42] T. Zhang, J. Jiang, B. Britton, B. Shollock, F. Dunne, Crack nucleation using combined crystal plasticity modelling, high-resolution digital image correlation and high-resolution electron backscatter diffraction in a superalloy containing non-metallic inclusions under fatigue, Proceedings of the Royal Society A: Mathematical, Physical and Engineering Science 472(2189) (2016).

[43] G. Cao, L. Fu, J. Lin, Y. Zhang, C. Chen, The relationships of microstructure and properties of a fully lamellar TiAl alloy, Intermetallics 8(5-6) (2000) 647-653.

[44] M.H. Yoo, Slip, twinning, and fracture in hexagonal close-packed metals, MTA 12(3) (1981) 409418.

[45] M.H. Yoo, J.R. Morris, K.M. Ho, S.R. Agnew, Nonbasal deformation modes of HCP metals and alloys: Role of dislocation source and mobility, Metall and Mat Trans A 33(13) (2002) 813-822.

[46] F. Appel, J.D.H. Paul, M. Oehring, Gamma titanium aluminide alloys : science and technology, Wiley-VCH, Weinheim, 2011.

[47] J.C. Stinville, W.C. Lenthe, J. Miao, T.M. Pollock, A combined grain scale elastic-plastic criterion for identification of fatigue crack initiation sites in a twin containing polycrystalline nickel-base superalloy, Acta Materialia 103 (2016) 461-473.

[48] Y.-W. Kim, H. Clemens, A.H. Rosenberger, Gamma titanium aluminides 2003, Minerals, Metals, \& Materials Society2003.

[49] R. Muñoz-Moreno, M.T. Pérez-Prado, J. Llorca, E.M. Ruiz-Navas, C.J. Boehlert, Effect of stress level on the high temperature deformation and fracture mechanisms of Ti-45Al-2Nb-2Mn- 0.8 vol. pct $\mathrm{TiB}_{2}$ : An in situ experimental study, Metall and Mat Trans A 44(4) (2013) 1887-1896.

[50] T.E.J. Edwards, Recent progress in the high-cycle fatigue behaviour of $\gamma$-TiAl alloys, Materials Science and Technology (2018) 1-21.

[51] R.M. Fisher, J.S. Lally, Microplasticity detected by an acoustic technique, Canadian Journal of Physics 45(2) (1967) 1147-1159.

[52] T.E.J. Edwards, F. Di Gioacchino, G. Mohanty, J. Wehrs, J. Michler, W.J. Clegg, Longitudinal twinning in a TiAl alloy at high temperature by in situ microcompression, Acta Materialia 148 (2018) 202-215.

[53] T.E.J. Edwards, F. Di Gioacchino, R. Muñoz-Moreno, W.J. Clegg, The interaction of borides and longitudinal twinning in polycrystalline TiAl alloys, Acta Materialia 140(Supplement C) (2017) 305-316.

[54] G. Hénaff, A.-L. Gloanec, Fatigue properties of TiAl alloys, Intermetallics 13(5) (2005) 543-558. 
[55] D. Rugg, M. Dixon, J. Burrows, High-temperature application of titanium alloys in gas turbines.

Material life cycle opportunities and threats - an industrial perspective, Materials at High Temperatures 33(4-5) (2016) 536-541.

[56] A.H. Cottrell, Theory of brittle fracture in steel and similar metals, Trans. Met. Soc. AIME 212 (1958).

[57] B.C. Ng, B.A. Simkin, M.A. Crimp, T.R. Bieler, The role of mechanical twinning on microcrack nucleation and crack propagation in a near- $\gamma$ TiAl alloy, Intermetallics 12(12) (2004) 1317-1323.

[58] A.W. Mello, T.A. Book, A. Nicolas, S.E. Otto, C.J. Gilpin, M.D. Sangid, Distortion Correction Protocol for Digital Image Correlation after Scanning Electron Microscopy: Emphasis on Long Duration and Ex-Situ Experiments, Experimental Mechanics (2017). 


\section{Figure Captions}

Figure 1 (a) Macroscale tensile specimen geometry (not to scale); (b) tensile loading curves for the four test conditions; black dots indicate the successive stress levels to which the sample was loaded before imaging of the speckle pattern was performed in the unloaded state. Black crosses indicate specimen failure, at which the speckle pattern was imaged a final time.

Figure 2 Backscatter electron imaging (a,c,e,g) and diffraction orientation mapping (b,d,f,h) of the region of interest of the testpieces in both the thicker (as-HIPped) and thinner (air-cooled) lamellar conditions for tensile testing below the general yield stress at 25 and $700{ }^{\circ} \mathrm{C}$.

Figure 3 Digital image correlation strain maps of the region of the thicker lamellar condition sample in Fig. 2(a) following tensile loading at $25{ }^{\circ} \mathrm{C}$ to $64 \%$ (a) and $82 \%$ (b) of the yield stress, and finally to failure (c). The black arrows indicate the few small dust particles on the pattern surface; the red arrows indicate the occurrence of sub-yield plasticity, which is consistently longitudinal; the green arrows indicate slip bands where the local shear strain at failure significantly exceeds that in the bands which were operative in the sub-yield regime. If image features are not clear, please refer to online version.

Figure 4 Lineplots of the local shear strain developed along slip lines arising during tensile testing of the thick lamellar condition to successively higher loads; extracted from the locations numbered in Fig. 3 and 6, after a 10 point averaging to reduce the regular oscillations in strain along deformation lines from the rectangular pixelation of DIC mapping. Black arrows indicate where the shear strain reaches a minimum at the edge of the colonies. The blue arrows in (e) indicate the locations where the slip line intersects a boride particle, and hence the shear stress drops to zero. The shear strain noise threshold is indicated by a horizontal black line on each plot. No bands nucleated between $64 \%$ and $82 \% \sigma_{\mathrm{y}}$ at $700{ }^{\circ} \mathrm{C}$.

Figure 5 Overlay of DIC, EBSD and backscatter electron imaging (BSE) data of regions undergoing longitudinal plasticity when compressed at $25^{\circ} \mathrm{C}$ (a) and $700{ }^{\circ} \mathrm{C}$ (b) to $82 \%$ of the respective yield stresses.

Figure 6 Digital image correlation strain maps of the region of the thicker lamellar condition sample in Fig. 2(c) following tensile loading at $700{ }^{\circ} \mathrm{C}$ to $64 \%$ (a) and $82 \%$ (b) of the yield stress, and finally to failure (c). The red arrow indicates the occurrence of sub-yield plasticity; the green arrows indicate slip bands where the local shear strain at failure significantly exceeds that in the band which was operative in the sub-yield regime. If image features are not clear, please refer to online version.

Figure 7 Digital image correlation strain maps of the regions of the refined lamellar condition sample in Fig. 2(e,g) following tensile loading at 25 and $700{ }^{\circ} \mathrm{C}$ to $64 \%(\mathrm{a}, \mathrm{c})$ and $82 \%$ $(\mathrm{b}, \mathrm{d})$ of the yield stress, respectively, and finally to failure above the general yield stress (e). The arrows have the same meaning as in Fig. 3. Casting porosity in the gauge section 
caused the air-cooled condition specimen to fail below the macroscopic yield point at $25^{\circ} \mathrm{C}$. If image features are not clear, please refer to online version.

Figure 8 Numbers of longitudinal slip lines produced per loading step (in percentages of the respective yield stress) for the $230 \times 200 \mu \mathrm{m}^{2}$ areas of interest in each condition.

Figure 9 Illustrations of the different strain transfer mechanisms at colony boundaries: direct strain transfer between longitudinal (L-L) systems is operative at $25^{\circ} \mathrm{C}$ (a) and $700{ }^{\circ} \mathrm{C}$ (b), direct transfer from a longitudinal to a transverse (L-T) system is seen at $25^{\circ} \mathrm{C}$ (c) and finally strain transfer by operation of lattice rotation is seen at $700{ }^{\circ} \mathrm{C}(\mathrm{d}, \mathrm{e})$ and can be resolved for the in-plane lattice rotation component $\theta_{3}$ (f). Colony boundary debonding where no strain transfer mechanisms are evident is shown in $(\mathrm{g}, \mathrm{h})$. The red lines indicate the traces of the lamellar interfaces at the sample surface.

Figure 10 Loading curves for the micropillars compressed at $25^{\circ} \mathrm{C}$ (a) and $700{ }^{\circ} \mathrm{C}$ (b). The dots indicate the vertical normal strain of the pillar measured from DIC strain mapping. The systematic deviation between the macroscopically measured strains and the DIC values is likely due to a combination of the potentially relatively large errors associated with $e x$-situ SEM imaging for DIC strain mapping work [58] and pillar sink-in that was not corrected for. The reason for minor tensile loading of the pillars at $700{ }^{\circ} \mathrm{C}$ upon unloading is explained elsewhere [52].

Figure 11 Example plasticity analysis dataset of a micropillar compressed at $25^{\circ} \mathrm{C}$ : the pre- (a) and post-test (b) secondary electron images were correlated to produce the strain map in (f). The pre- (d) and post-test (e) EBSD maps indicate that the plastic regions are not associated with the occurrence of longitudinal deformation twinning. Arrows indicate the location of deformation lines and the type of lamellar interface along which they lie. The remainder of the micropillars compressed at room temperature are in $(g-r)$.

Figure 12 STEM BF (a,c,e,g) and HAADF (b,d,f,h) images of thin foil lift-outs of the pillars compressed at $25{ }^{\circ} \mathrm{C}$ in Fig. 11. The STEM images were taken along the $(111)_{\gamma}$ lamellar interfaces in order to minimise the imaged width of the lamellar boundaries. The white arrows indicate longitudinal slip lines in the $\gamma$ lamellae; black arrows indicate transverse twins. Shearing arrow pairs indicate longitudinally twinned regions. All $\alpha_{2}-\mathrm{Ti}_{3} \mathrm{Al}$ lamellae are annotated as such, based on the surface crystal orientation maps in Fig. 11; the remaining lamellae are $\gamma$-TiAl. $\mathrm{TiB}_{2}$ particles are arrowed in red. (a,b) are pillar 1, (c,d) 3, $(\mathrm{e}, \mathrm{f}) 4$ and $(\mathrm{g}, \mathrm{h}) 5$.

Figure 13 Pre- and post-compression EBSD maps, and DIC strain maps for the micropillars compressed at $700^{\circ} \mathrm{C}$. Arrows have the same meaning as in Fig. 11.

Figure 14 STEM BF (a,c,e,g) and HAADF (b,d,f,h) images of thin foil lift-outs of the pillars compressed at $700{ }^{\circ} \mathrm{C}$ in Fig. 13. All annotated carry the same meaning as in Fig. 12. (a,b) is pillar $6,(\mathrm{c}, \mathrm{d}) 7$, (e,f) 8 and $(\mathrm{g}, \mathrm{h}) 9$. 
Table 1 Nominal and measured compositions of the titanium aluminide alloy studied. Note that the boron content in Ti4522XD exceeds the maximum measurable by ASTM E2371.

\begin{tabular}{|c|c|c|c|c|c|c|c|c|c|c|}
\hline & $\begin{array}{c}\mathrm{Ti} \\
\text { /at.\% }\end{array}$ & $\begin{array}{c}\mathrm{Al} \\
/ \text { at. } \%\end{array}$ & $\begin{array}{c}\mathrm{Nb} \\
/ \text { at. } \%\end{array}$ & $\begin{array}{l}\mathrm{Mn} \\
\text { /at.\% }\end{array}$ & $\begin{array}{c}\mathrm{TiB}_{2} \\
\text { /vol. \% }\end{array}$ & $\begin{array}{c}\mathrm{O} \\
\text { /at. } \%\end{array}$ & N /at.\% & C /at.\% & H /at. \% & $\begin{array}{l}\mathrm{Mo}, \mathrm{Cu}, \mathrm{Si}, \\
\mathrm{Fe}, \mathrm{Ni}, \mathrm{Cr}, \\
\text { W, Co, V, } \\
\mathrm{Sn}, \mathrm{Bi}, \mathrm{Pb}, \\
\mathrm{Zr}, \mathrm{P} / \mathrm{at} .\end{array}$ \\
\hline Nominal & bal. & 45 & 2 & 2 & 0.8 & 0 & 0 & 0 & 0 & 0 \\
\hline $\begin{array}{l}\text { Measured, } \\
\text { matrix only } \\
\left(\mathrm{TiB}_{2}\right. \\
\text { excluded })\end{array}$ & bal. & 44.7 & 1.8 & 1.8 & - & 0.21 & 0.05 & 0.03 & 0.04 & $\leq 0.01$ \\
\hline
\end{tabular}

Table 2 Microstructural characteristics of Ti4522XD in the as-HIPped and air cooled (refined) lamellar conditions determined by EBSD and TKD measurements, respectively. The average domain length was calculated by measuring the total length of $\gamma$-TiAl lamellae contained within the rectangular regions of interest within single colonies, and dividing by the number of domain boundaries within the region to determine the average spacing between successive domain boundaries in any direction in the lamellar planes. Numbers in brackets are the lamellar interface proportions considering only $\gamma / \gamma$ types. 
Table 3 Stresses and strains achieved at each loading step, with the elastic strains calculated from literature values for the Young's modulus of the $\alpha_{2}-\mathrm{Ti}_{3} \mathrm{Al}$ and $\gamma$-TiAl phases [29], and a rule of mixtures from the material compositions in Table 2 . * casting porosity not removed by HIPping was noted in the gauge section. ** Low, negative strain values of strain occur as a result of the plastic strain being below the noise threshold of the DIC measurement.

\begin{tabular}{|c|c|c|c|c|c|}
\hline & \multicolumn{2}{|c|}{ As-received condition } & \multicolumn{2}{|c|}{$\begin{array}{l}\text { Refined lamellae } \\
\text { condition }\end{array}$} \\
\hline & & $25^{\circ} \mathrm{C}$ & $700^{\circ} \mathrm{C}$ & $25^{\circ} \mathrm{C}$ & $700^{\circ} \mathrm{C}$ \\
\hline \multirow{3}{*}{$\begin{array}{c}1^{\text {st }} \text { step } \\
\left(64 \% \sigma_{\mathrm{y}}\right)\end{array}$} & Stress /MPa & 350 & 255 & 350 & 305 \\
\hline & $\begin{array}{l}\text { Elastic strain } \\
\quad \text { (calc.) }\end{array}$ & $0.21 \%$ & $0.17 \%$ & $0.21 \%$ & $0.21 \%$ \\
\hline & Plastic strain (DIC) & $0.16 \%$ & $0.00 \% * *$ & $-0.04 \% * *$ & $0.04 \%$ \\
\hline \multirow{3}{*}{$\begin{array}{l}2^{\text {nd }} \text { step } \\
\left(82 \% \sigma_{\mathrm{y}}\right)\end{array}$} & Stress /MPa & 450 & 327 & - & 393 \\
\hline & $\begin{array}{l}\text { Elastic strain } \\
\text { (calc.) }\end{array}$ & $0.26 \%$ & $0.22 \%$ & - & $0.27 \%$ \\
\hline & Plastic strain (DIC) & $0.18 \%$ & $-0.05 \% * *$ & - & $0.14 \%$ \\
\hline $\begin{array}{l}\text { Yield point } \\
\text { (from } \\
\text { samples } \\
\text { without DIC) }\end{array}$ & Yield stress /MPa & $550[22]$ & $400[22]$ & 550 & 480 \\
\hline \multirow[t]{2}{*}{ Failure } & $\begin{array}{l}\text { Ultimate tensile } \\
\text { stress } / \mathrm{MPa}\end{array}$ & 590 & 592 & $384 *$ & 587 \\
\hline & Plastic strain (DIC) & $0.69 \%$ & $1.57 \%$ & $-0.07 \% * *$ & $0.15 \%$ \\
\hline
\end{tabular}


Table 4 Distribution of axial strain in micropillars between regions containing, and external to, the longitudinal microplasticity bands; calculations were made using geometric masking functions in DaVis. * The low, positive value of $\varepsilon_{\mathrm{yy}, \mathrm{ext}}$ for pillar \#6 (producing a $P$ above $100 \%$ ) is likely a result of unusually high noise in the strain map.

\begin{tabular}{|c|c|c|c|c|c|c|c|}
\hline \multirow{2}{*}{$\begin{array}{c}\text { Test } \\
\text { temperature } \\
{ }^{\circ} \mathrm{C}\end{array}$} & \multirow[b]{2}{*}{ Pillar \# } & \multirow{2}{*}{$\begin{array}{l}\text { Full } \\
\text { pillar } \\
\varepsilon_{\mathrm{yy}, \mathrm{avg}}\end{array}$} & \multicolumn{2}{|c|}{ Longitudinal bands } & \multicolumn{2}{|c|}{ Remainder of pillar } & \multirow[b]{2}{*}{$P$} \\
\hline & & & $\begin{array}{c}\varepsilon_{\mathrm{yy}, \mathrm{band}} \\
\text { (average) }\end{array}$ & $\begin{array}{l}A_{\text {band }} \\
\text { (arb. } \\
\text { units) }\end{array}$ & $\begin{array}{c}\varepsilon_{\mathrm{yy}, \mathrm{ext}} \\
\text { (average) }\end{array}$ & $\begin{array}{c}A_{\text {ext }} \\
\text { (arb. } \\
\text { units) }\end{array}$ & \\
\hline \multirow{5}{*}{25} & 1 & $-0.47 \%$ & $-4.25 \%$ & 822 & $-0.03 \%$ & 7056 & $94.4 \%$ \\
\hline & 2 & $-1.04 \%$ & $-2.95 \%$ & 1543 & $-0.58 \%$ & 6196 & $56.6 \%$ \\
\hline & 3 & $-0.80 \%$ & $-5.27 \%$ & 808 & $-0.30 \%$ & 6816 & $69.8 \%$ \\
\hline & 4 & $-0.88 \%$ & $-3.47 \%$ & 489 & $-0.69 \%$ & 7164 & $25.2 \%$ \\
\hline & 5 & $-0.93 \%$ & $-6.86 \%$ & 1001 & $-0.10 \%$ & 7023 & $92.0 \%$ \\
\hline \multirow{4}{*}{700} & 6 & $-0.35 \%$ & $-3.86 \%$ & 941 & $0.12 \% *$ & 6442 & $-*$ \\
\hline & 7 & $-0.96 \%$ & $-2.98 \%$ & 968 & $-0.72 \%$ & 6256 & $41.6 \%$ \\
\hline & 8 & $-0.72 \%$ & $-4.55 \%$ & 767 & $-0.32 \%$ & 6066 & $70.9 \%$ \\
\hline & 9 & $-1.33 \%$ & $-4.65 \%$ & 1438 & $-0.44 \%$ & 6166 & $66.1 \%$ \\
\hline
\end{tabular}



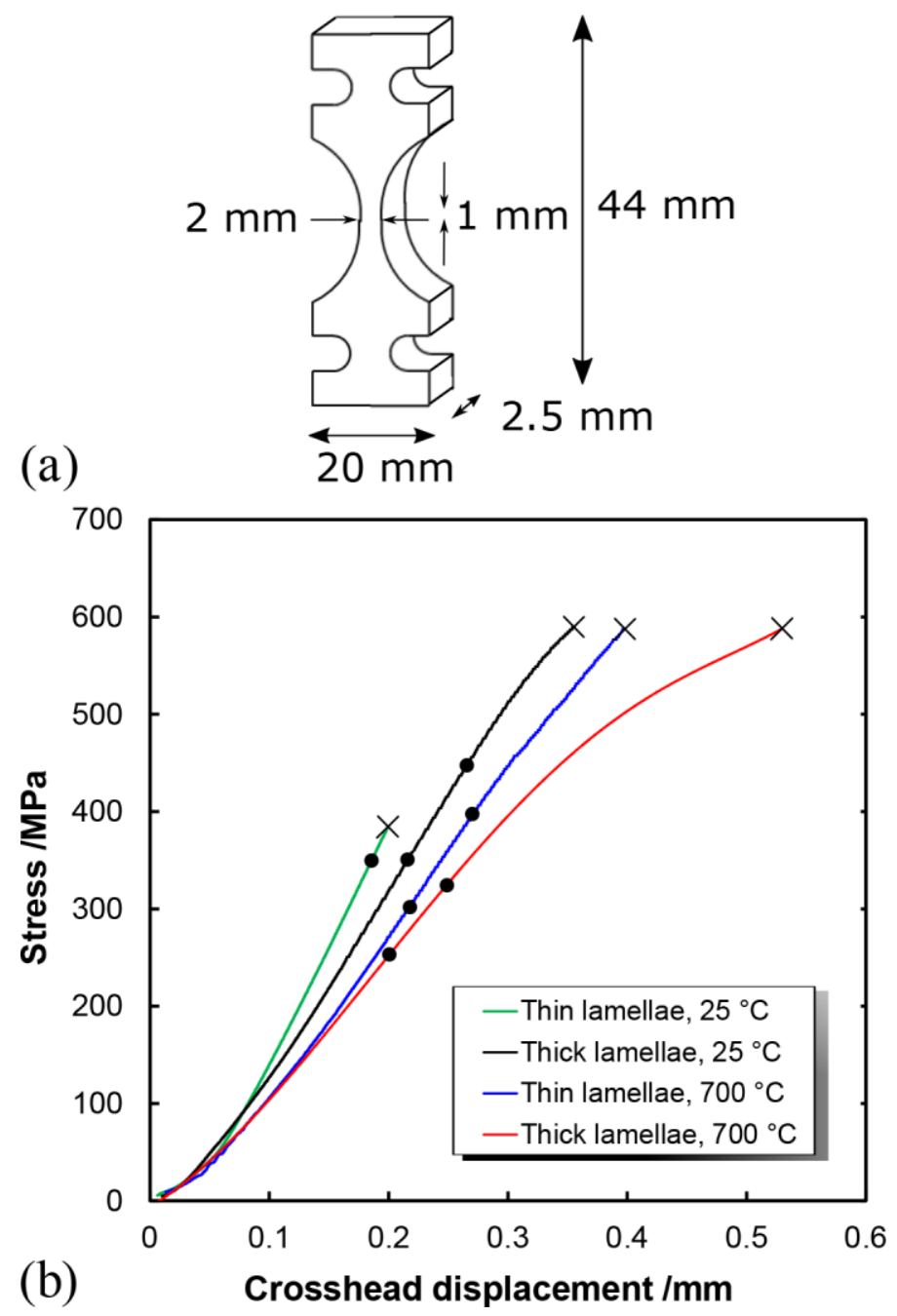

Figure 1 (a) Macroscale tensile specimen geometry (not to scale); (b) tensile loading curves for the four test conditions; black dots indicate the successive stress levels to which the sample was loaded before imaging of the speckle pattern was performed in the unloaded state. Black crosses indicate specimen failure, at which the speckle pattern was imaged a final time. 


\section{Thick lamellae}

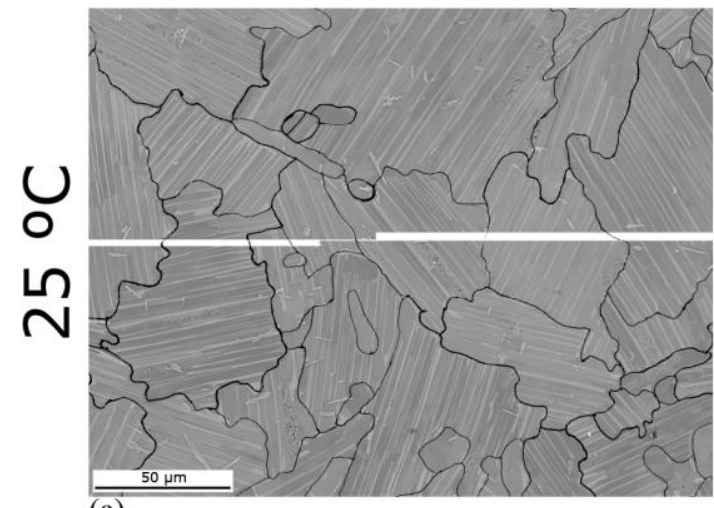

(a)
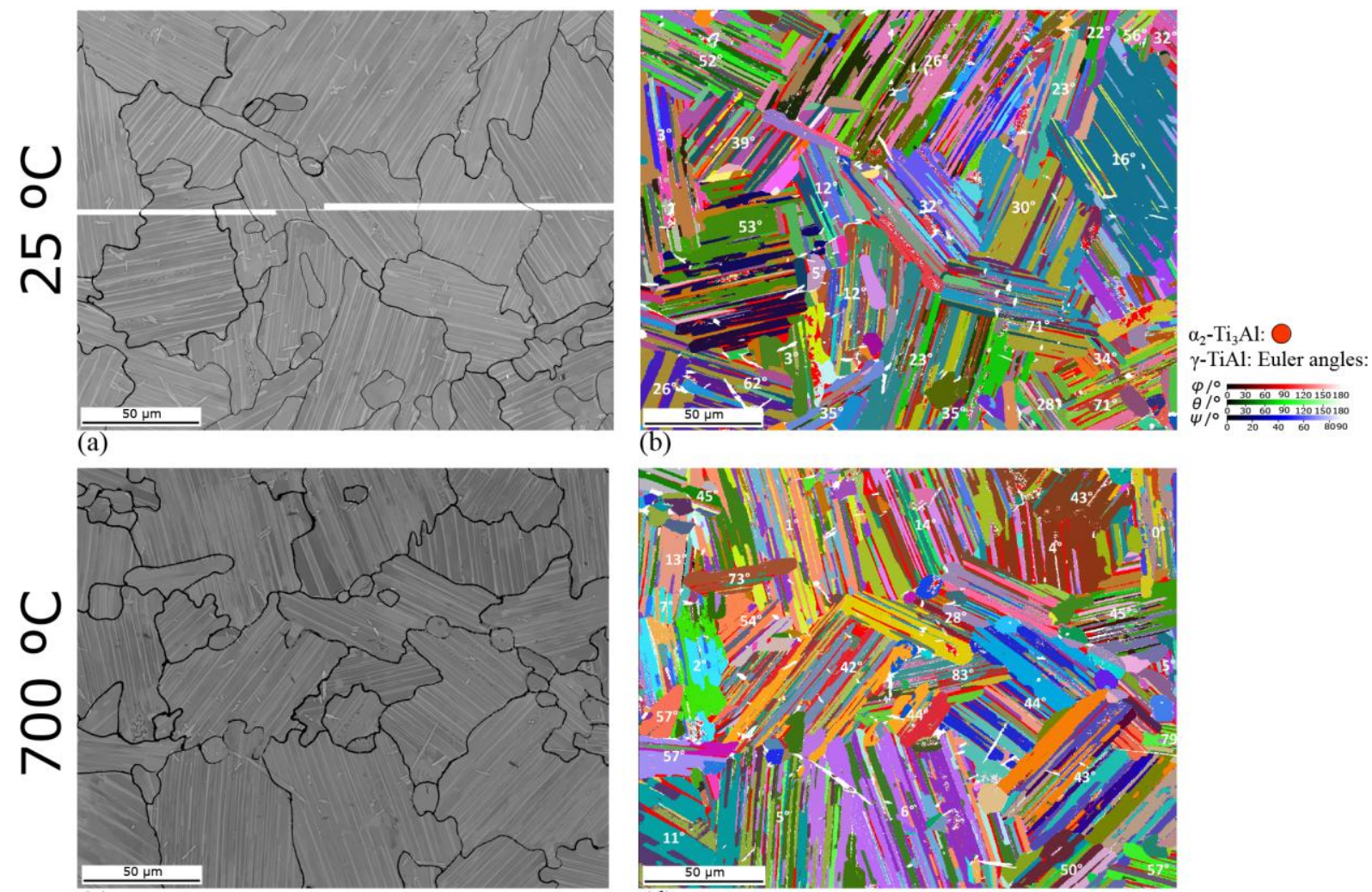

(c)

(b)

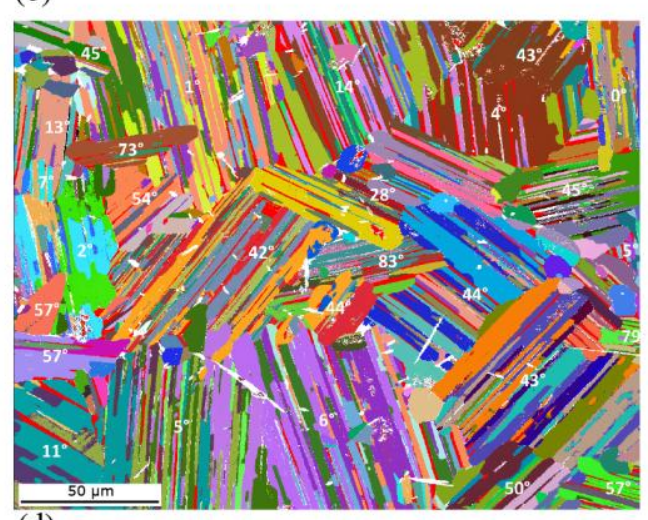

(d)

\section{Thin lamellae}

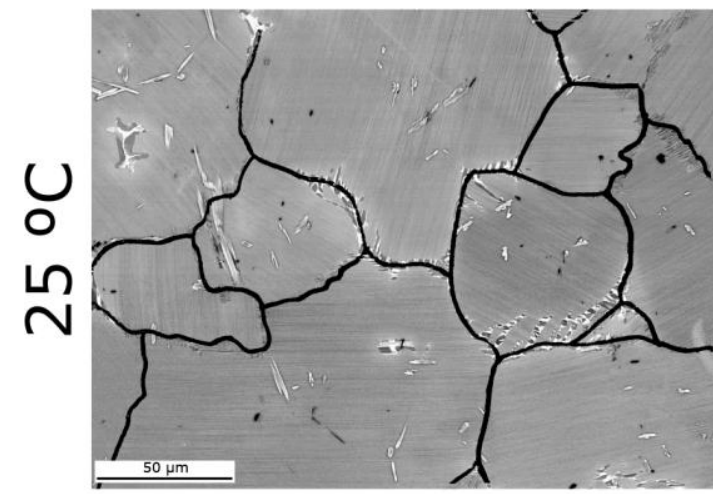

(e)

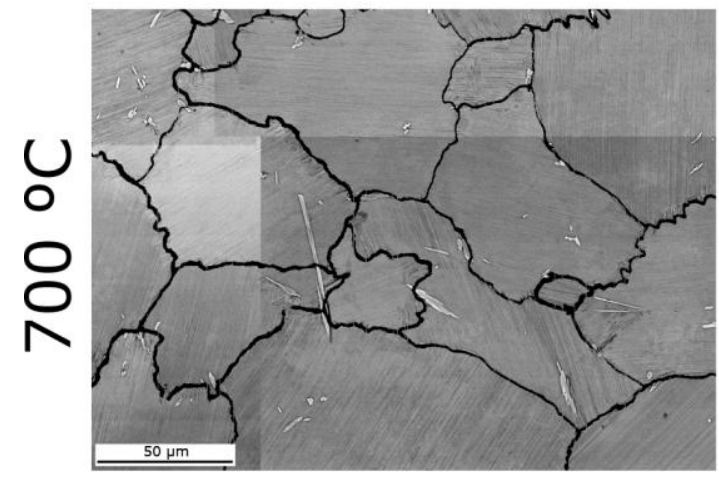

(g)

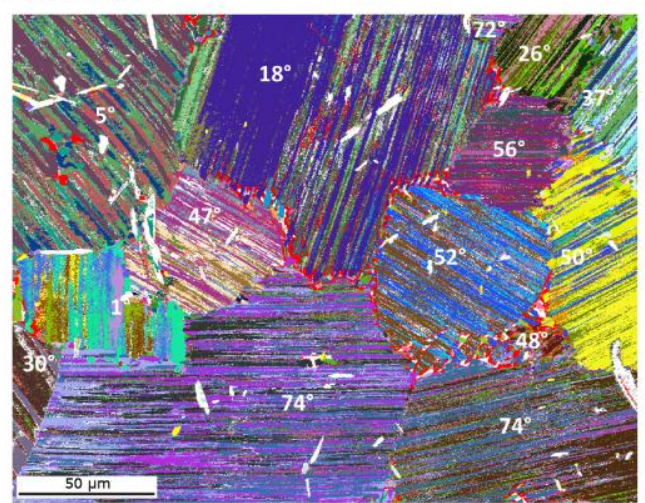

(f)

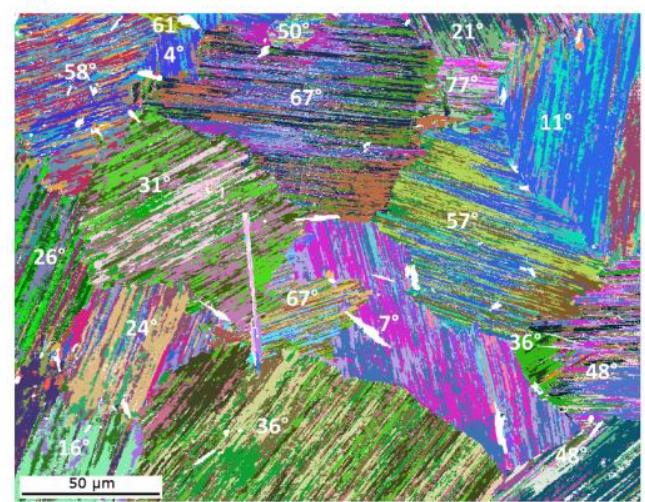

(h)

Figure 2 Backscatter electron imaging (a,c,e,g) and diffraction orientation mapping (b,d,f,h) of the region of interest of the testpieces in both the thicker (as-HIPped) and thinner (air-cooled) lamellar conditions for tensile testing below the general yield stress at 25 and $700{ }^{\circ} \mathrm{C}$. 
Thick lamellae, $25^{\circ} \mathrm{C}$

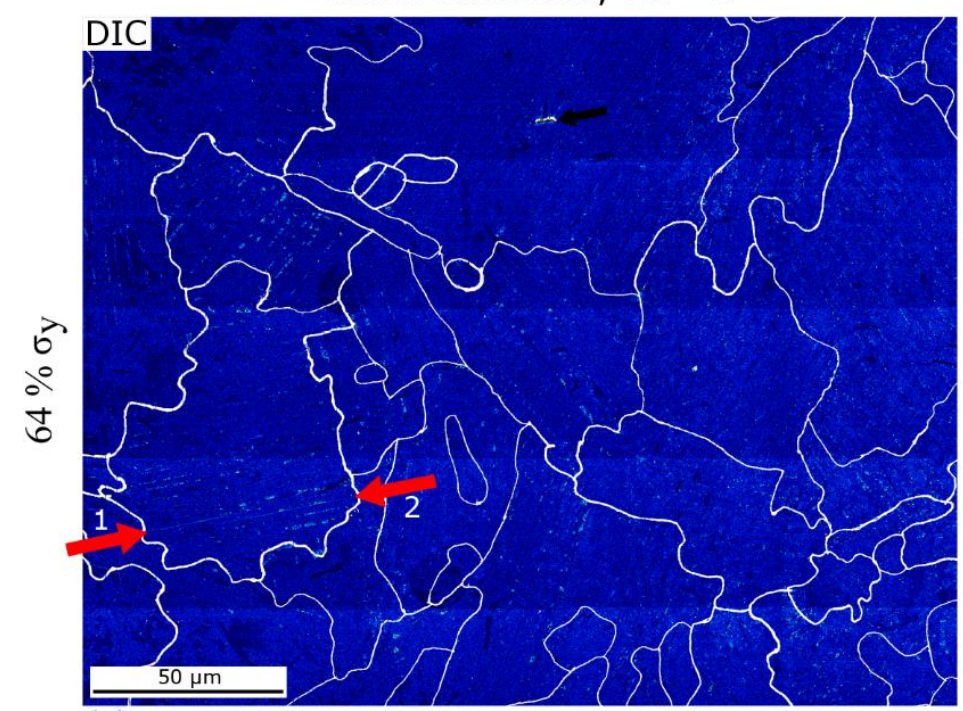

(a)

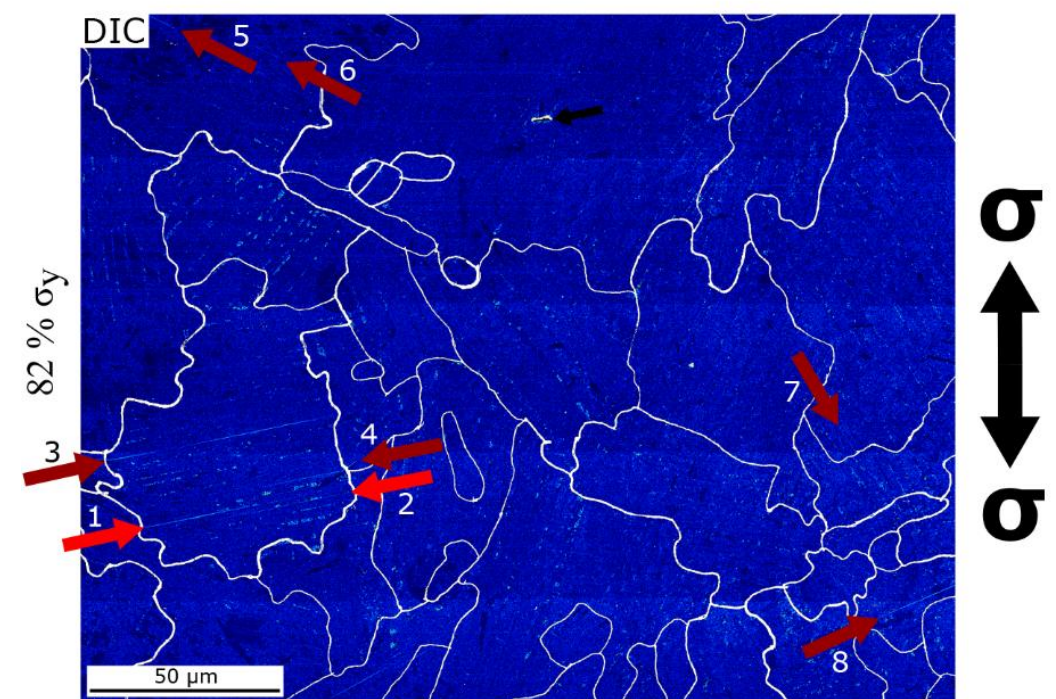

(b)

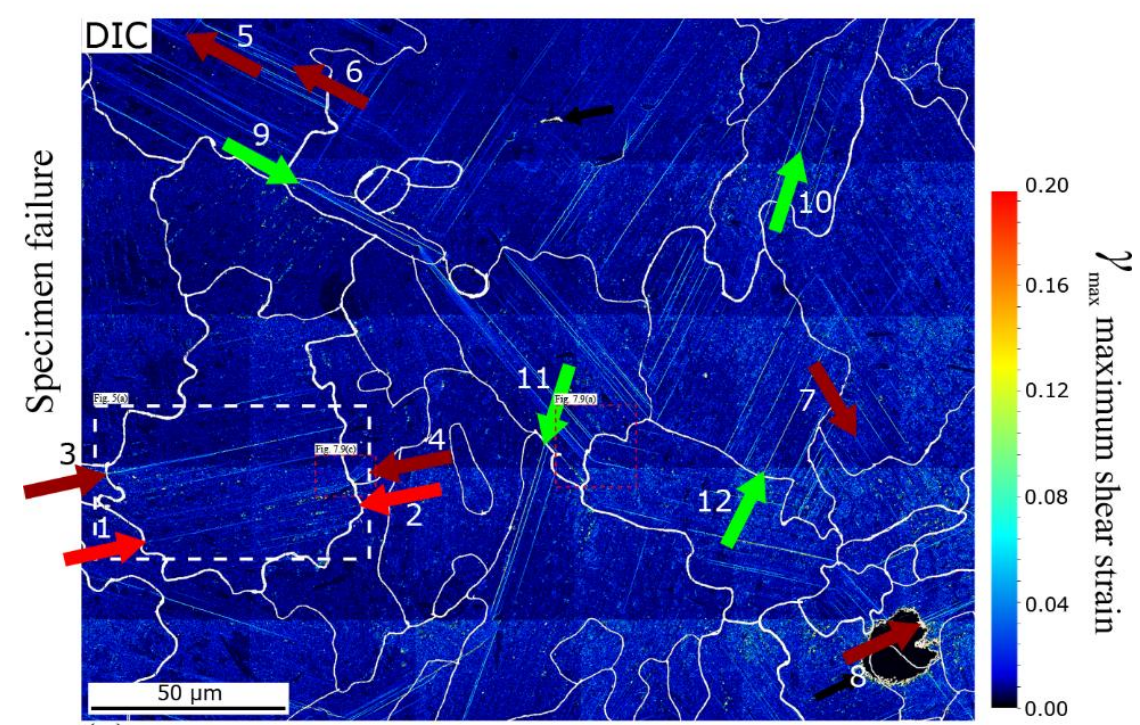

(c)

Figure 3 Digital image correlation strain maps of the region of the thicker lamellar condition sample in Fig. 2(a) following tensile loading at $25{ }^{\circ} \mathrm{C}$ to $64 \%$ (a) and $82 \%$ (b) of the yield stress, and finally to failure (c). The black arrows indicate the few small dust particles on the pattern surface; the red arrows indicate the occurrence of sub-yield plasticity, which is consistently longitudinal; the green arrows indicate slip bands where the local shear strain at failure significantly exceeds that in the bands which were operative in the sub-yield regime. If image features are not clear, please refer to online version. 


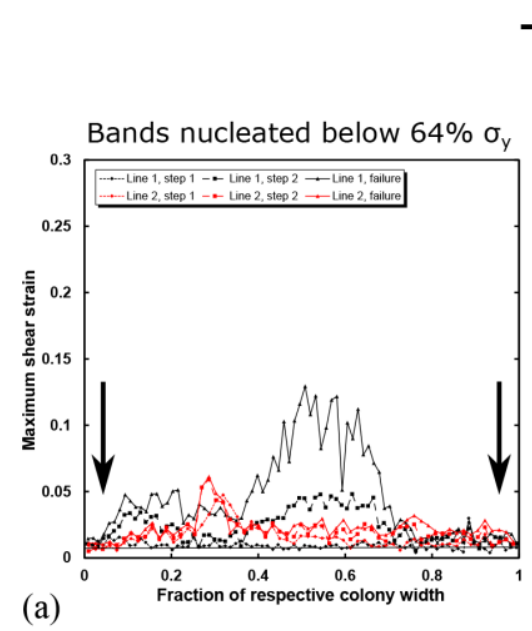

Thick lamellae, $25^{\circ} \mathrm{C}$

Bands nucleated between

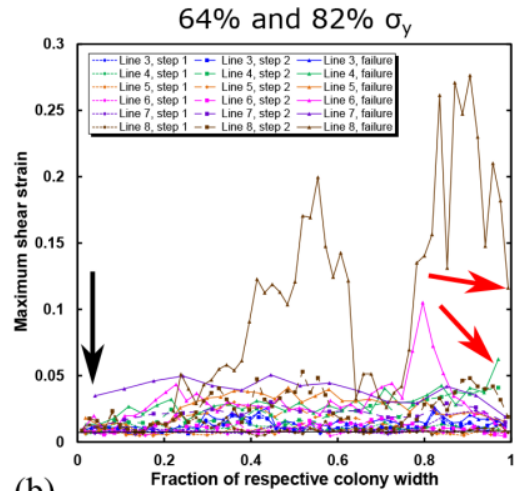

(b)

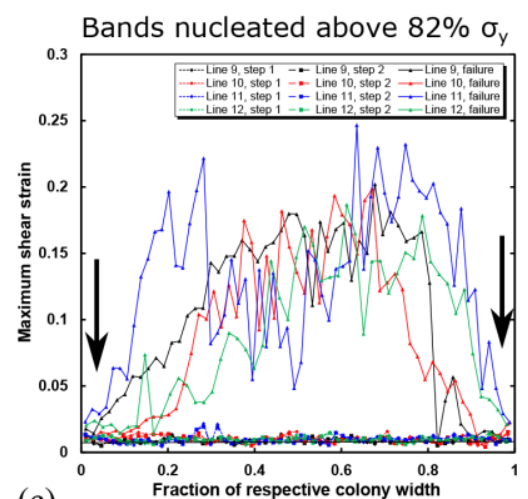

(c)

Thick lamellae, $7000^{\circ} \mathrm{C}$

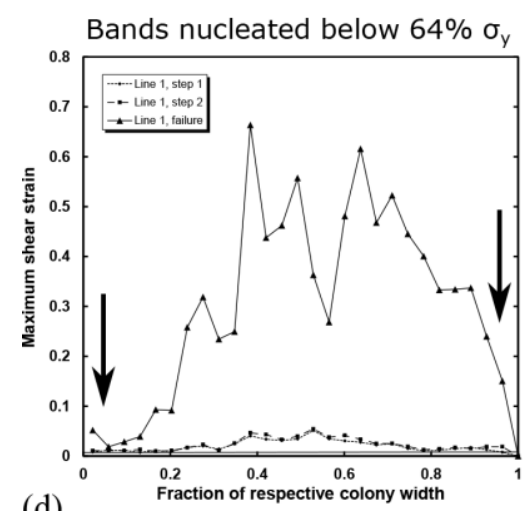

Bands nucleated between

$64 \%$ and $82 \% \sigma_{y}$

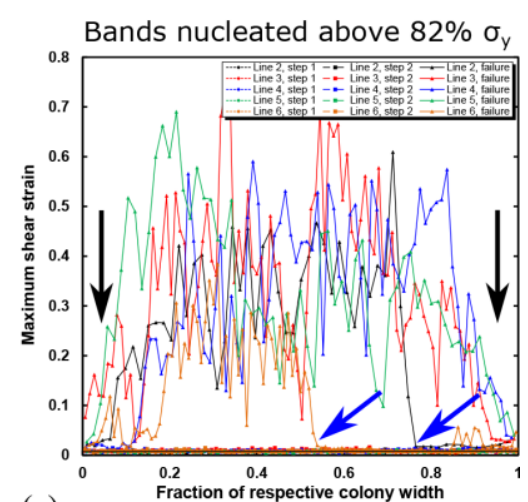

(e)

Figure 4 Lineplots of the local shear strain developed along slip lines arising during tensile testing of the thick lamellar condition to successively higher loads; extracted from the locations numbered in Fig. 3 and 6, after a 10 point averaging to reduce the regular oscillations in strain along deformation lines from the rectangular pixelation of DIC mapping. Black arrows indicate where the shear strain reaches a minimum at the edge of the colonies. The blue arrows in (e) indicate the locations where the slip line intersects a boride particle, and hence the shear stress drops to zero. The shear strain noise threshold is indicated by a horizontal black line on each plot. No bands nucleated between $64 \%$ and $82 \% \sigma_{\mathrm{y}}$ at $700{ }^{\circ} \mathrm{C}$. 

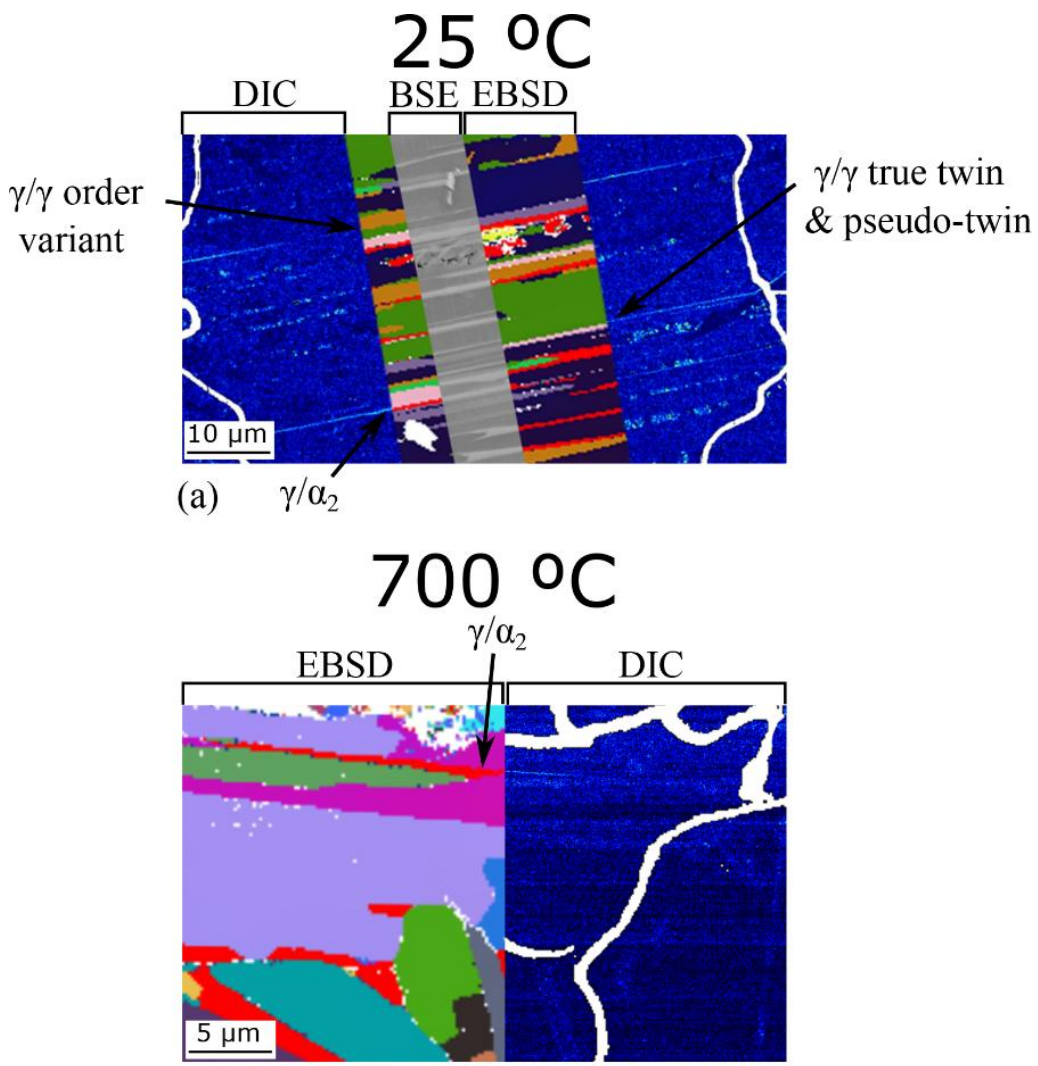

(b)

Figure 5 Overlay of DIC, EBSD and backscatter electron imaging (BSE) data of regions undergoing longitudinal plasticity when compressed at $25{ }^{\circ} \mathrm{C}$ (a) and $700{ }^{\circ} \mathrm{C}$ (b) to $82 \%$ of the respective yield stresses. 
Thick lamellae, $700^{\circ} \mathrm{C}$

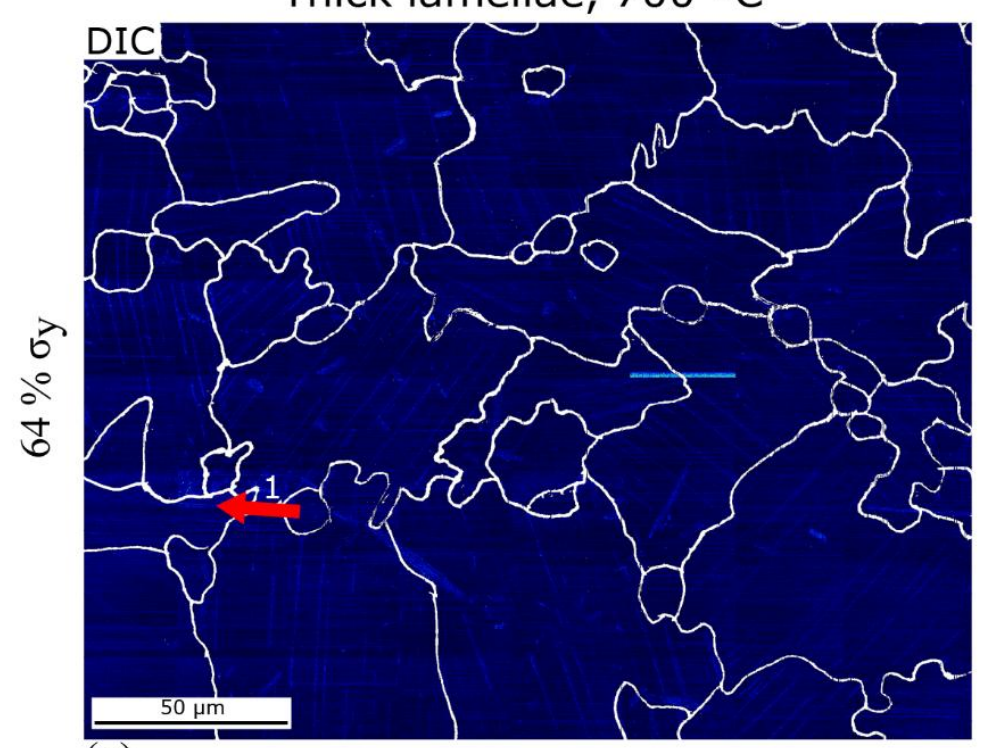

(a)

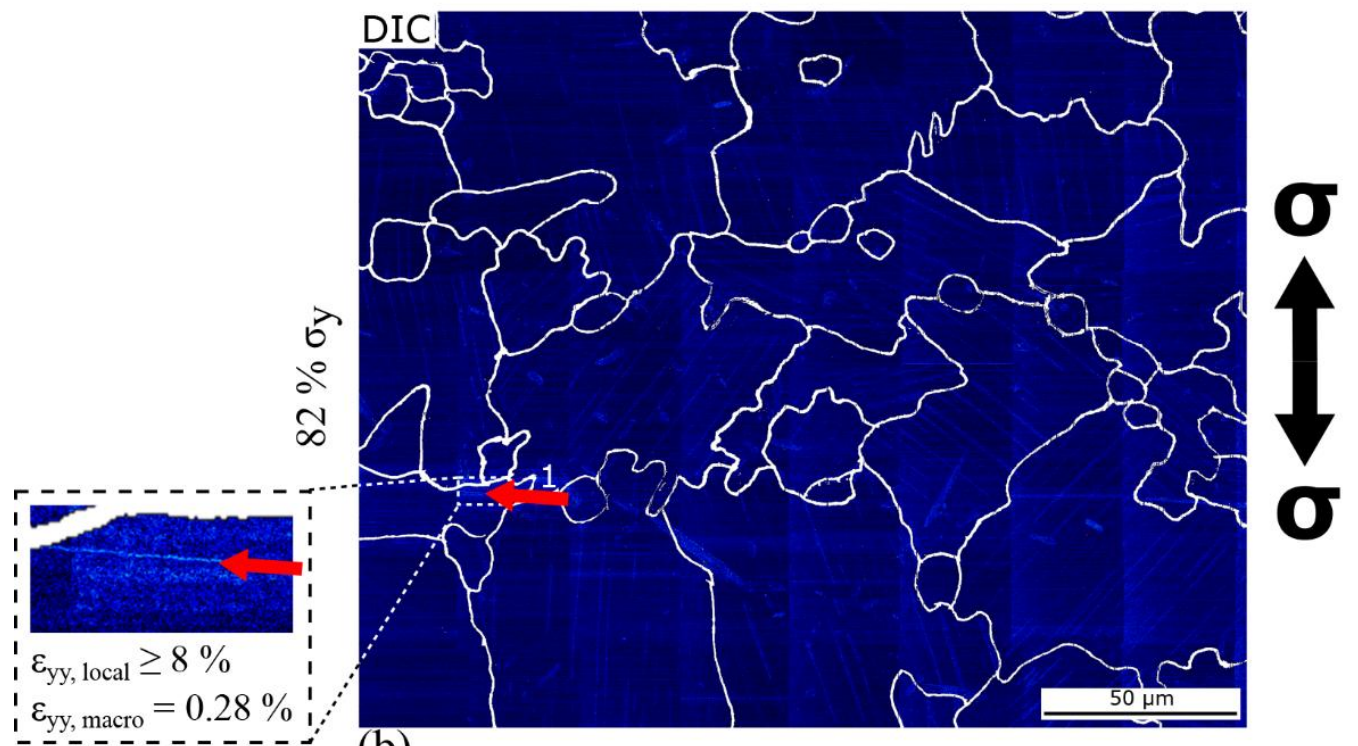

(b)

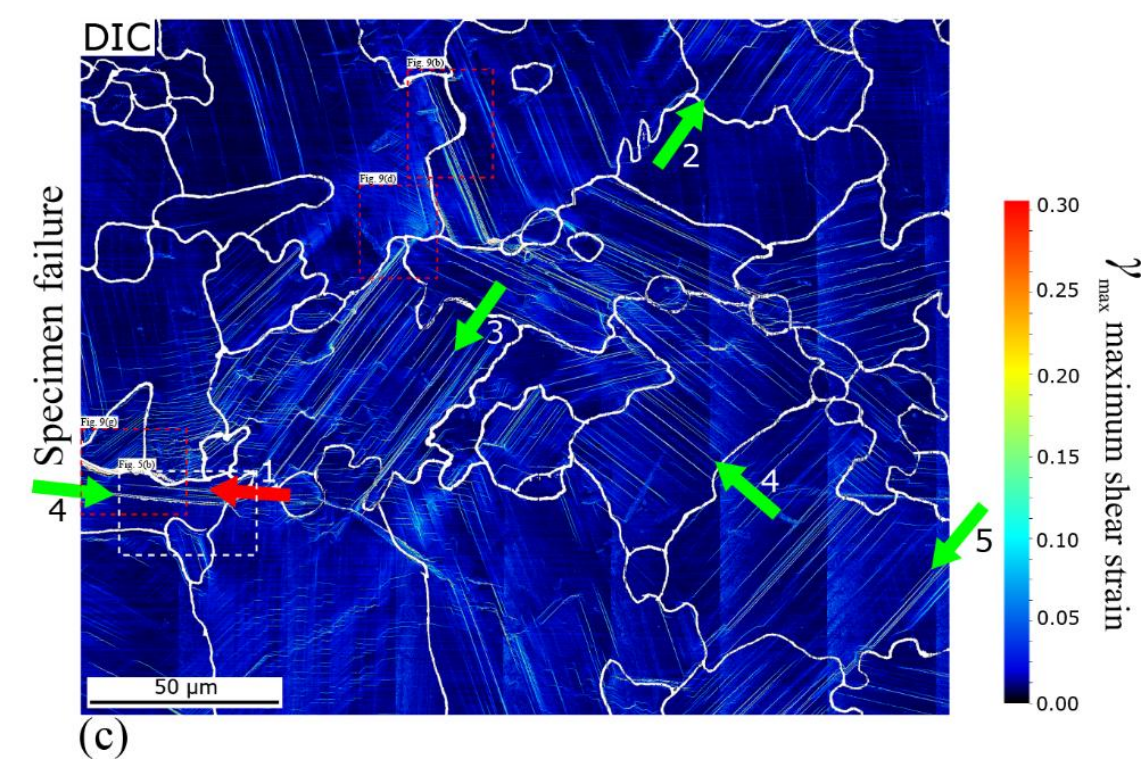

Figure 6 Digital image correlation strain maps of the region of the thicker lamellar condition sample in Fig. 2(c) following tensile loading at $700{ }^{\circ} \mathrm{C}$ to $64 \%$ (a) and $82 \%$ (b) of the yield stress, and finally to failure (c). The red arrow indicates the occurrence of sub-yield plasticity; the green arrows indicate slip bands where the local shear strain at failure significantly exceeds that in the band which was operative in the sub-yield regime. If image features are not clear, please refer to online version. 
Thin lamellae, $25^{\circ} \mathrm{C}$
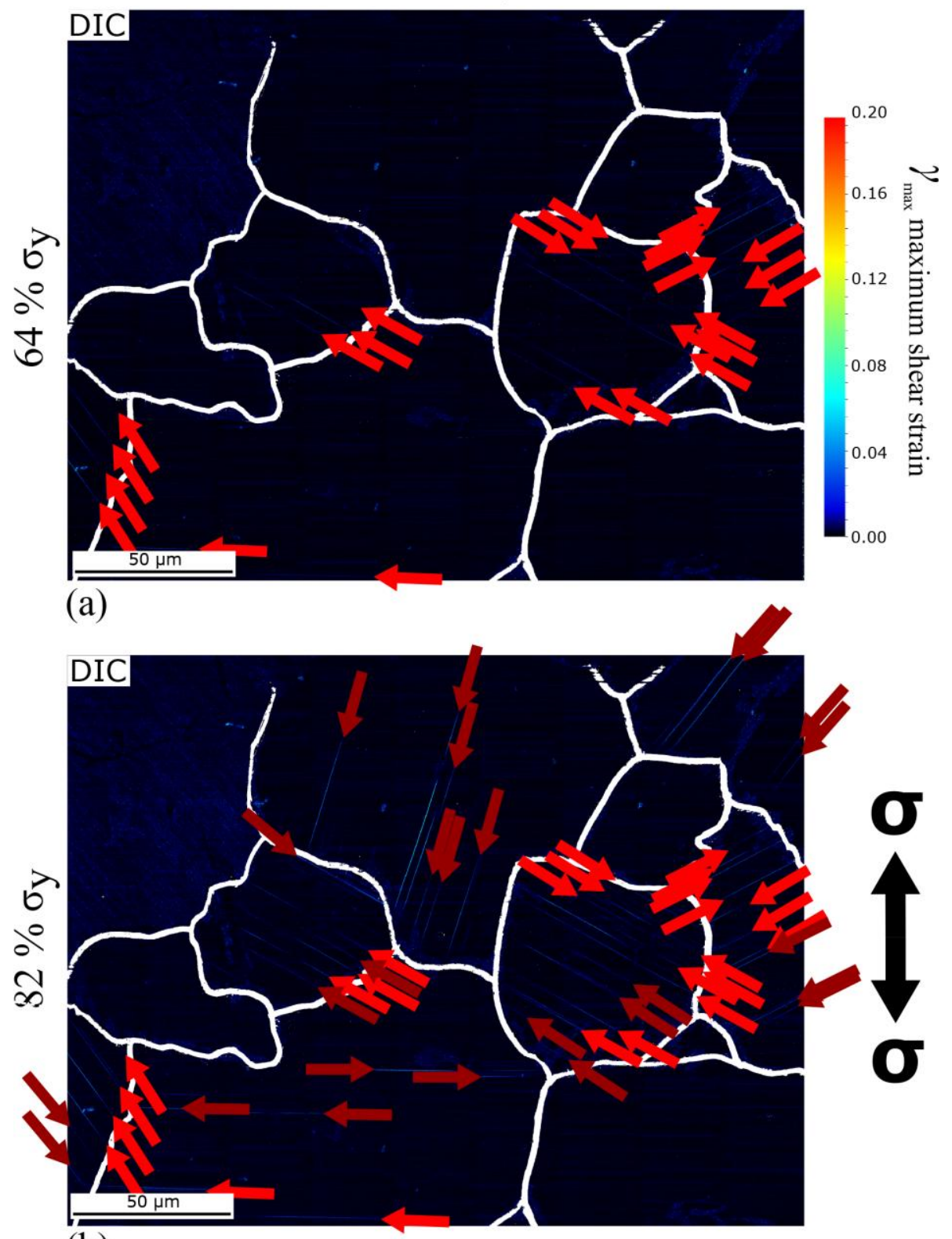

(b) 


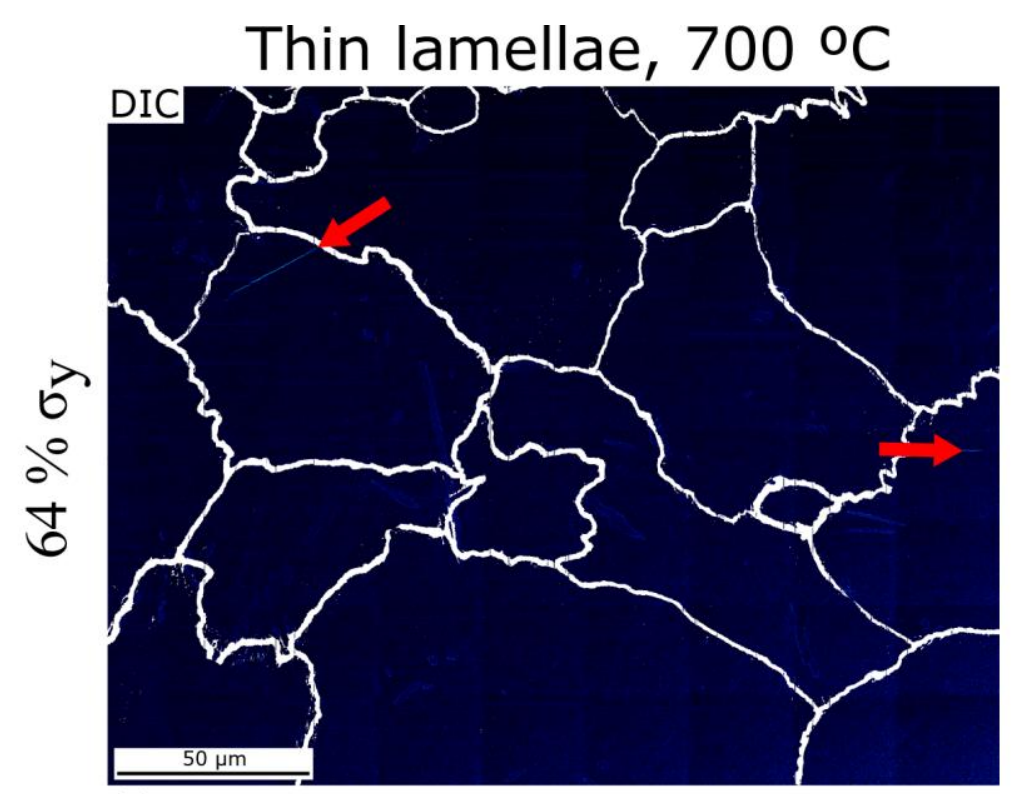

(c)

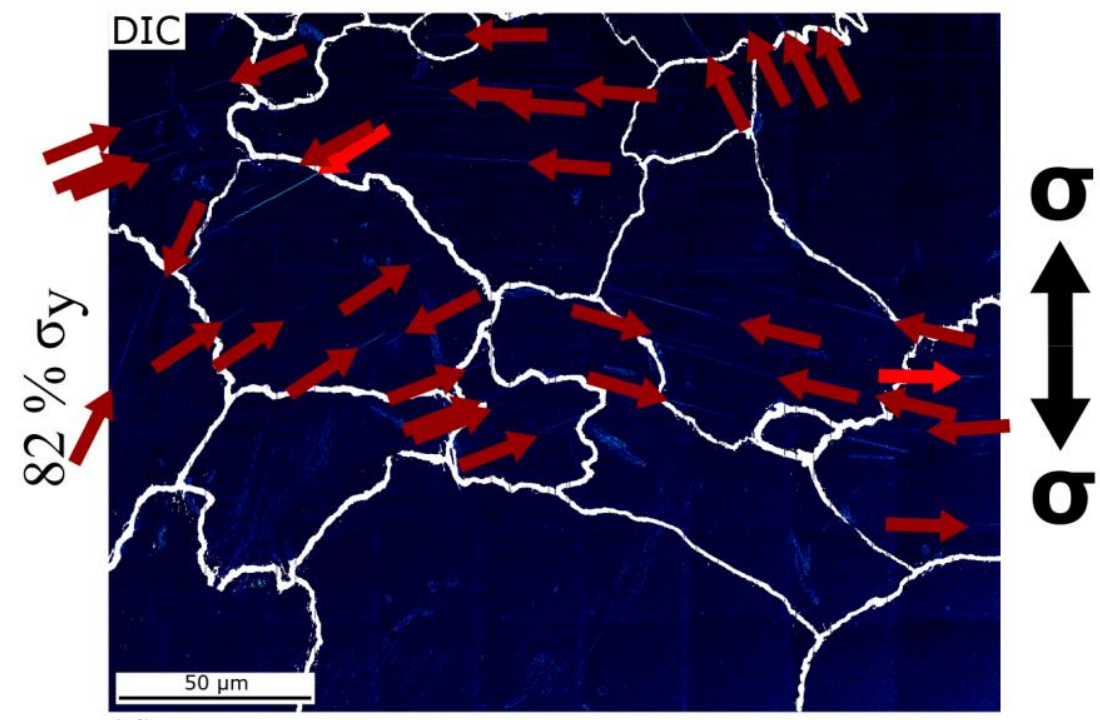

(d)

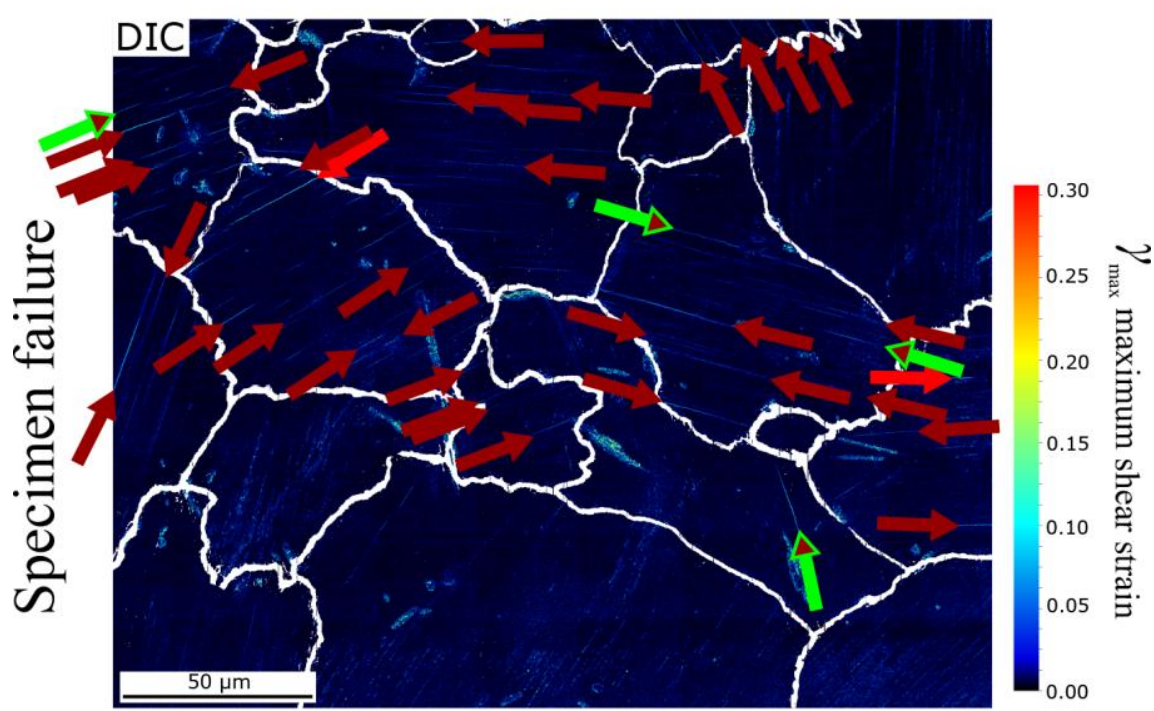

(e)

Figure 7 Digital image correlation strain maps of the regions of the refined lamellar condition sample in Fig. 2(e,g) following tensile loading at 25 and $700{ }^{\circ} \mathrm{C}$ to $64 \%(\mathrm{a}, \mathrm{c})$ and $82 \%(\mathrm{~b}, \mathrm{~d})$ of the yield stress, respectively, and finally to failure above the general yield stress (e). The arrows have the same meaning as in Fig. 3. Casting porosity in the gauge section caused the aircooled condition specimen to fail below the macroscopic yield point at $25{ }^{\circ} \mathrm{C}$. If image features are not clear, please refer to online version. 

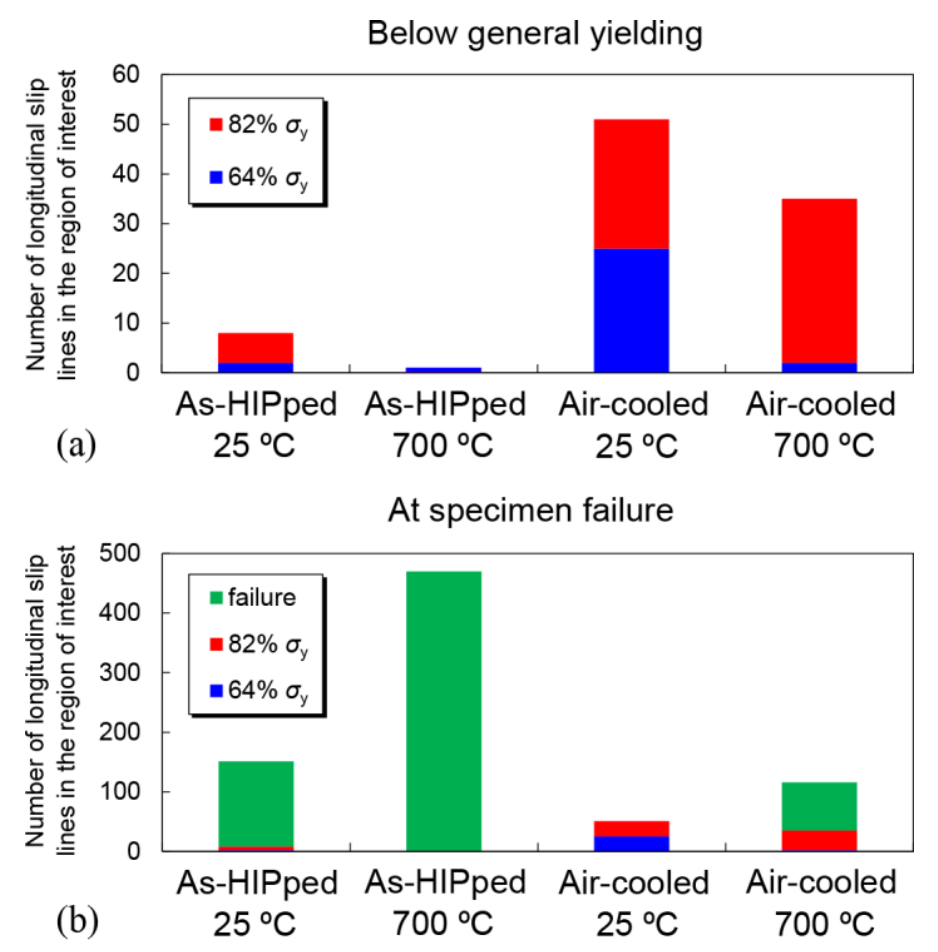

Figure $8 \quad$ Numbers of longitudinal slip lines produced per loading step (in percentages of the respective yield stress) for the $230 \times 200 \mu \mathrm{m}^{2}$ areas of interest in each condition. 


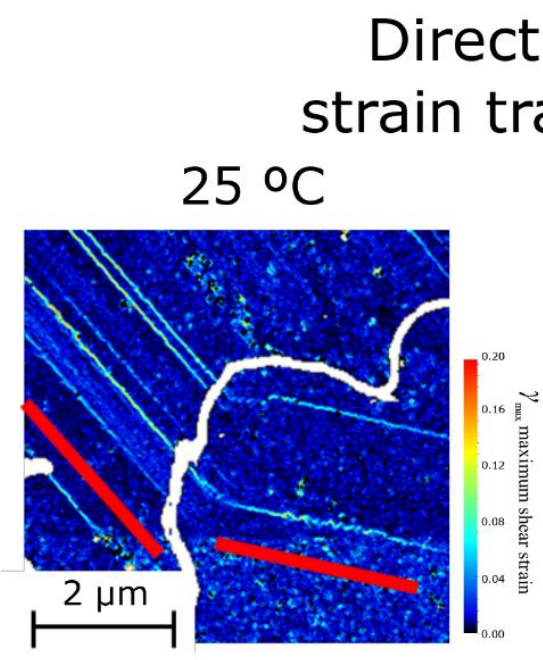

(a)

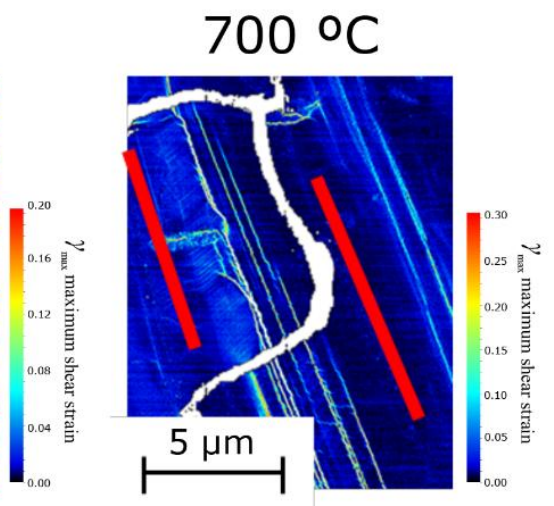

(b)

\section{Direct L-T \\ strain transfer}

$25^{\circ} \mathrm{C}$

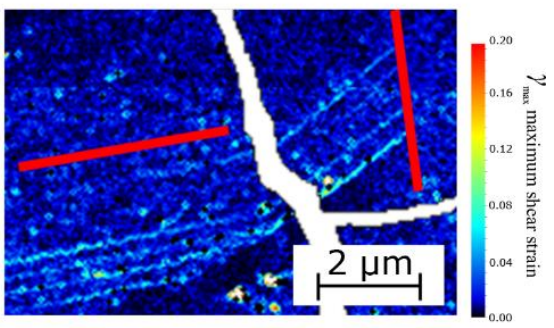

(c)

\section{Strain transfer by region of lattice rotation $700{ }^{\circ} \mathrm{C}$}

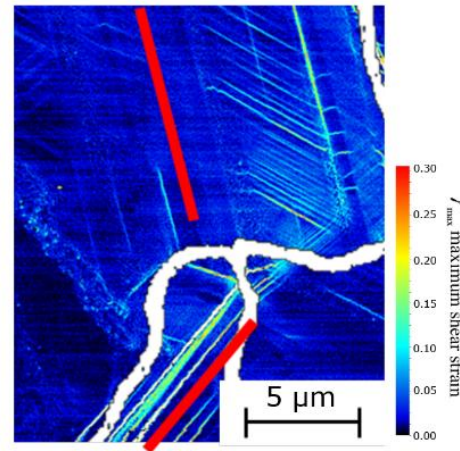

(d)

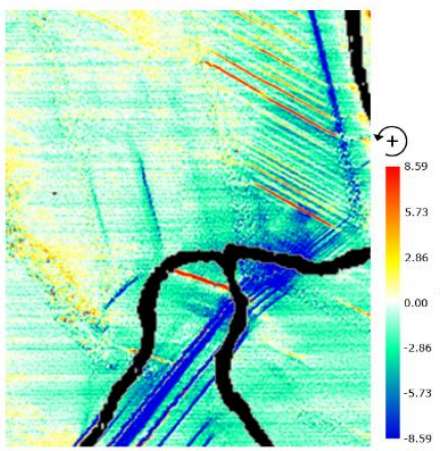

(e)

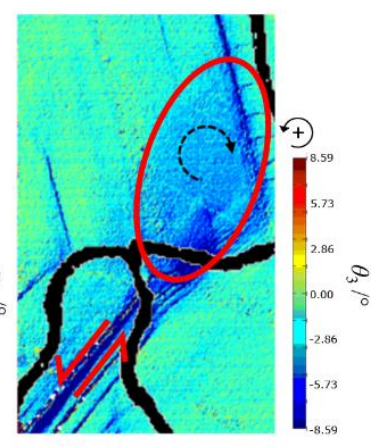

(f)

Colony boundary failure in the absence of direct strain transfer or strain transfer by lattice rotation

\section{$700^{\circ} \mathrm{C}$}

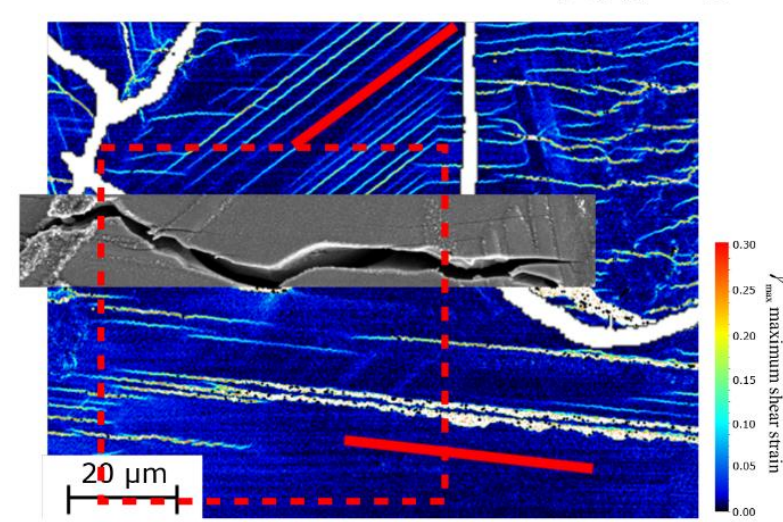

(g)

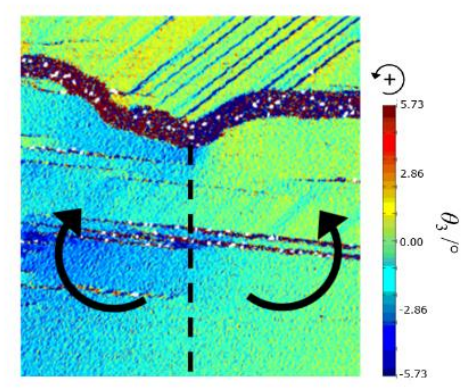

(h)

Figure 9 Illustrations of the different strain transfer mechanisms at colony boundaries: direct strain transfer between longitudinal (L-L) systems is operative at $25^{\circ} \mathrm{C}$ (a) and $700{ }^{\circ} \mathrm{C}$ (b), direct transfer from a longitudinal to a transverse (L-T) system is seen at $25^{\circ} \mathrm{C}$ (c) and finally strain transfer by operation of lattice rotation is seen at $700{ }^{\circ} \mathrm{C}(\mathrm{d}, \mathrm{e})$ and can be resolved for the inplane lattice rotation component $\theta_{3}$ (f). Colony boundary debonding where no strain transfer mechanisms are evident is shown in $(\mathrm{g}, \mathrm{h})$. The red lines indicate the traces of the lamellar interfaces at the sample surface. 

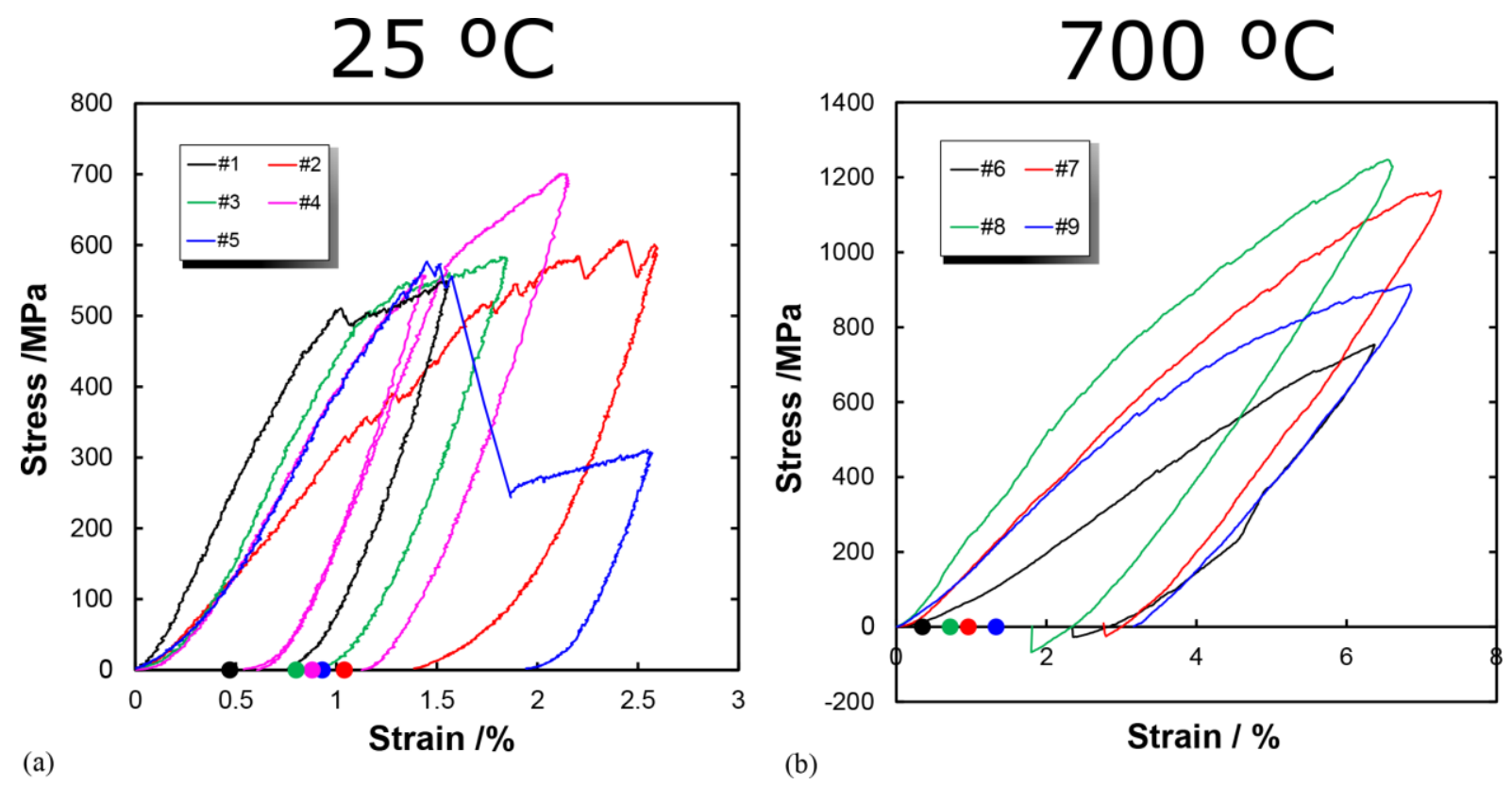

Figure 10 Loading curves for the micropillars compressed at $25{ }^{\circ} \mathrm{C}$ (a) and $700{ }^{\circ} \mathrm{C}$ (b). The dots indicate the vertical normal strain of the pillar measured from DIC strain mapping. The systematic deviation between the macroscopically measured strains and the DIC values is likely due to a combination of the potentially relatively large errors associated with ex-situ SEM imaging for DIC strain mapping work [56] and pillar sink-in that was not corrected for. The reason for minor tensile loading of the pillars at $700{ }^{\circ} \mathrm{C}$ upon unloading is explained elsewhere [51]. 

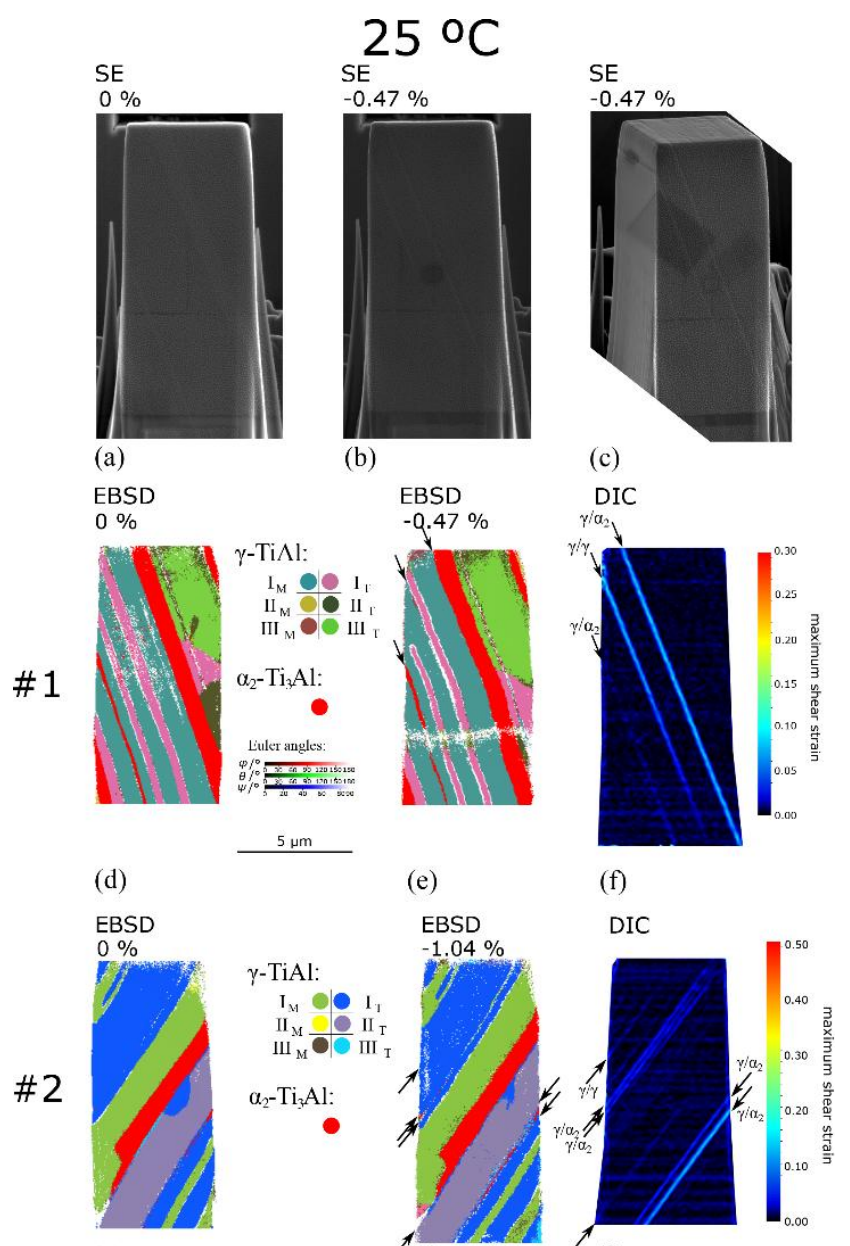

(e)

(f)
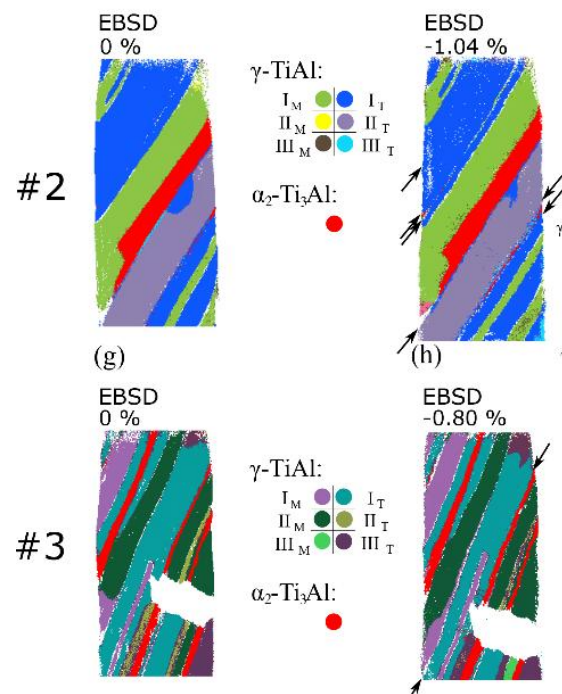

DIC
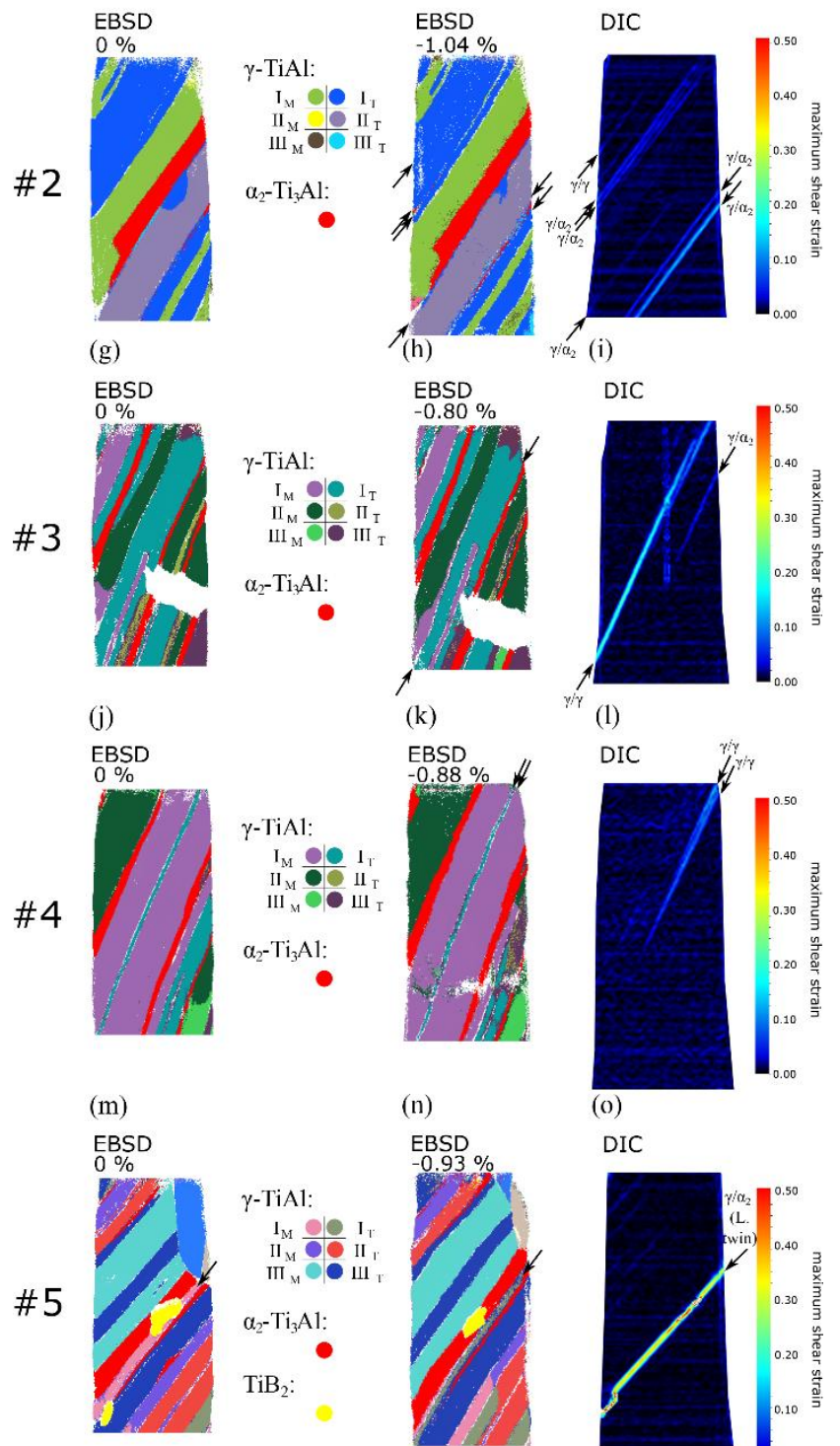

(n)
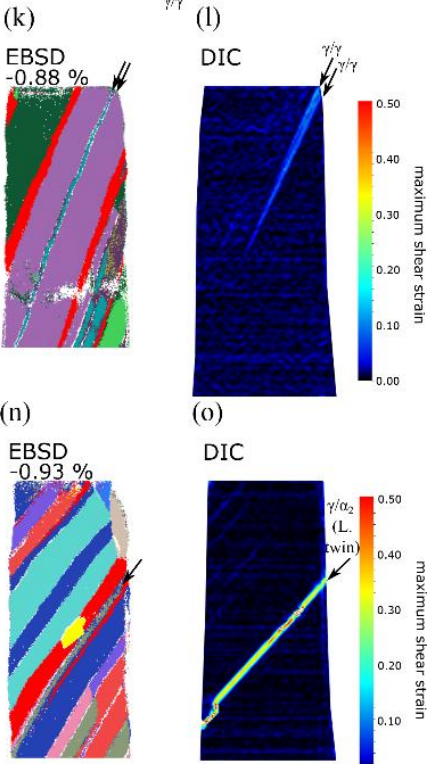

(o)

DIC

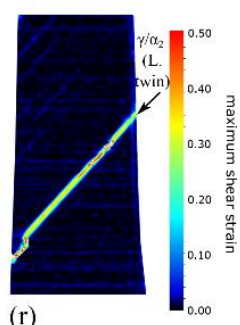

(p)

(q)

$(\mathrm{r})$

Figure 11 Example plasticity analysis dataset of a micropillar compressed at $25{ }^{\circ} \mathrm{C}$ : the pre- (a) and post-test (b) secondary electron images were correlated to produce the strain map in (f). The pre- (d) and post-test (e) EBSD maps indicate that the plastic regions are not associated with the occurrence of longitudinal deformation twinning. Arrows indicate the location of deformation lines and the type of lamellar interface along which they lie. The remainder of the micropillars compressed at room temperature are in $(g-r)$. 


\section{Pillar \#1}
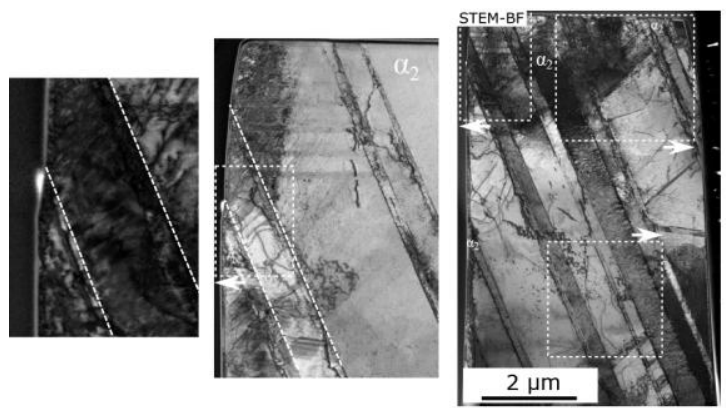

(a)
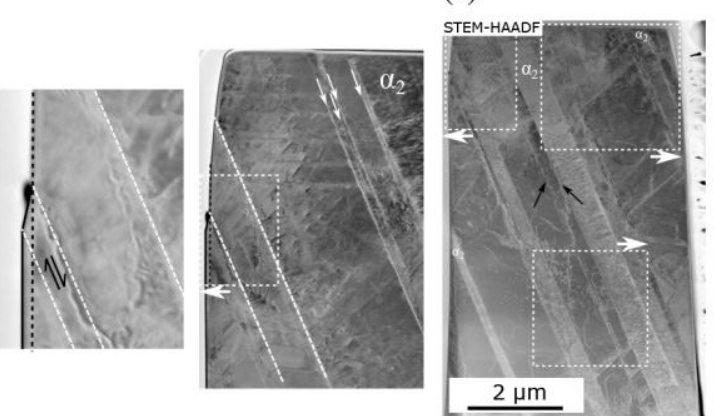

(b)

\#4
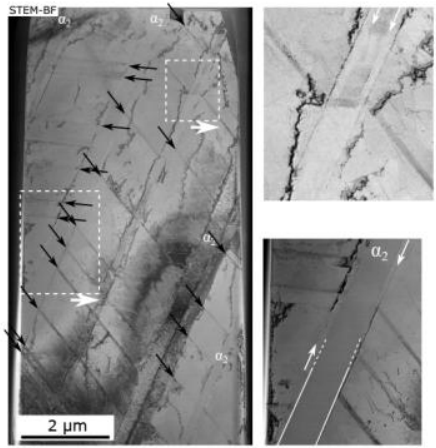

(e)

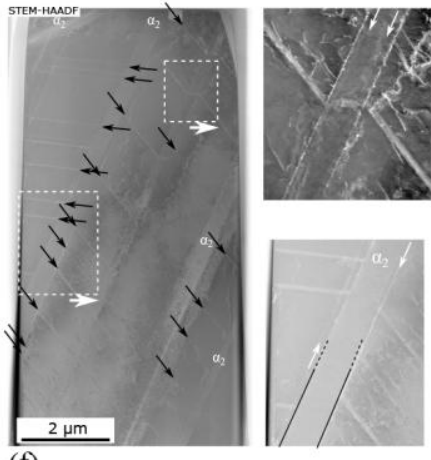

(f)
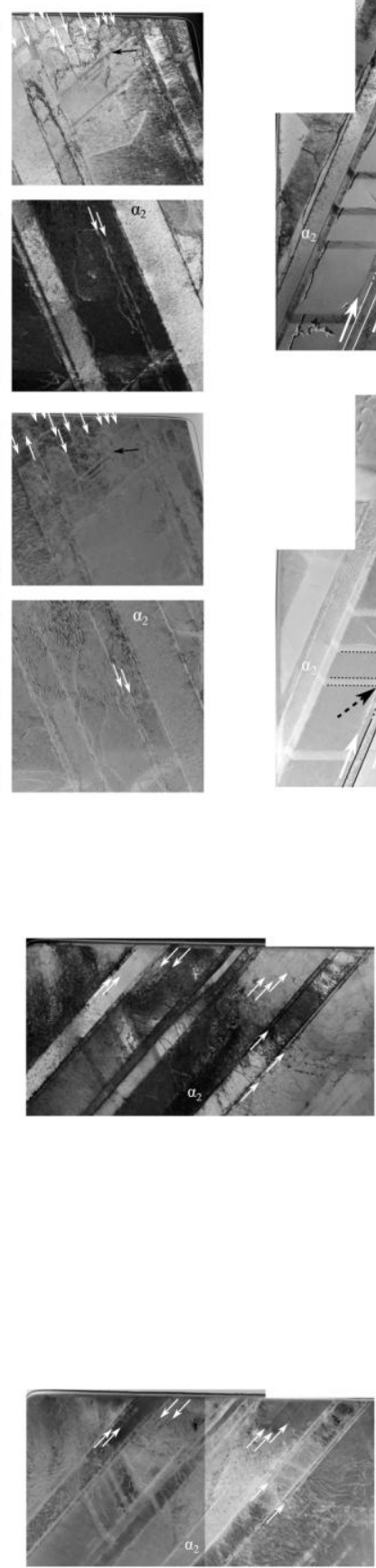
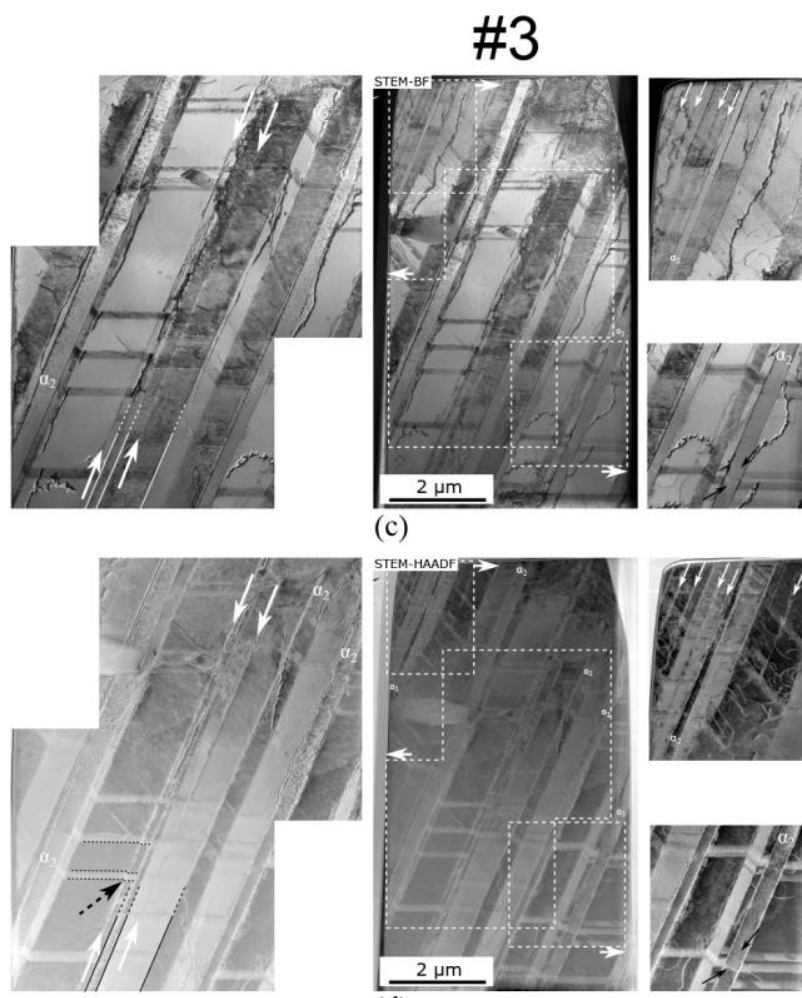

(c)
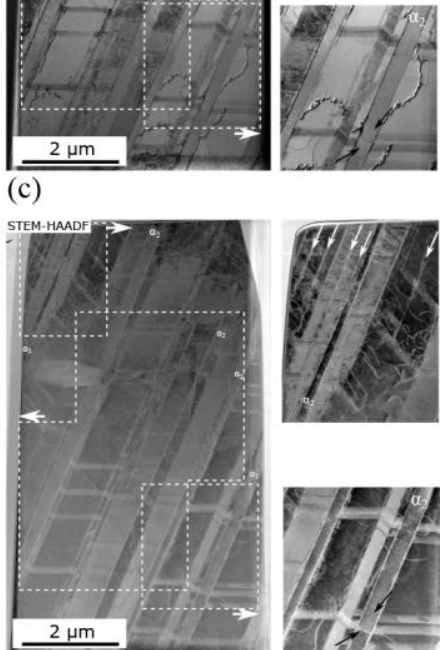

(d)

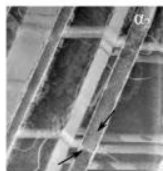

\#5
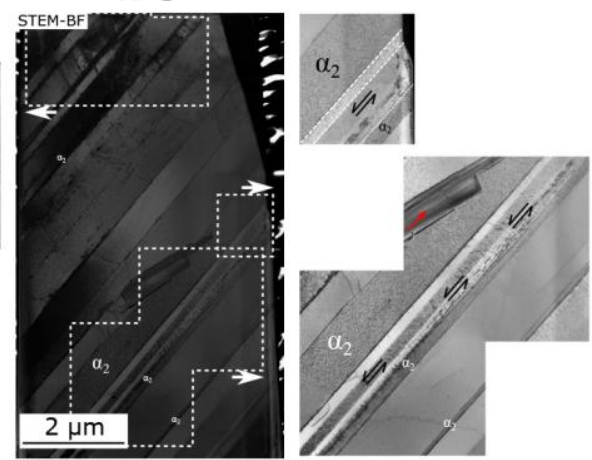

(g)
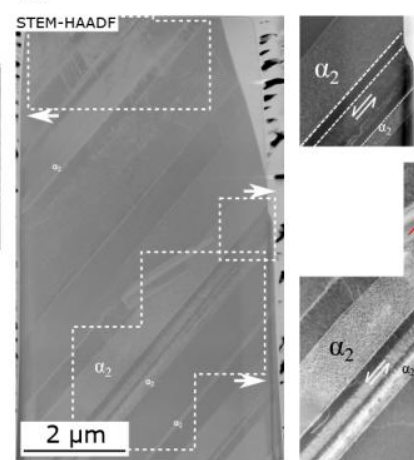

(h)

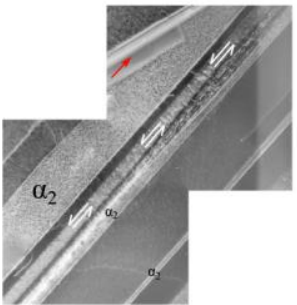

Figure 12 STEM BF (a,c,e,g) and HAADF (b,d,f,h) images of thin foil lift-outs of the pillars compressed at $25{ }^{\circ} \mathrm{C}$ in Fig. 11. The STEM images were taken along the $(111)_{\gamma}$ lamellar interfaces in order to minimise the imaged width of the lamellar boundaries. The white arrows indicate longitudinal slip lines in the $\gamma$ lamellae; black arrows indicate transverse twins. Shearing arrow pairs indicate longitudinally twinned regions. All $\alpha_{2}-\mathrm{Ti}_{3} \mathrm{Al}$ lamellae are annotated as such, based on the surface crystal orientation maps in Fig. 11; the remaining lamellae are $\gamma$-TiAl. $\mathrm{TiB}_{2}$ particles are arrowed in red. $(\mathrm{a}, \mathrm{b})$ are pillar $1,(\mathrm{c}, \mathrm{d}) 3$, (e,f) 4 and $(\mathrm{g}, \mathrm{h}) 5$. 
\#6

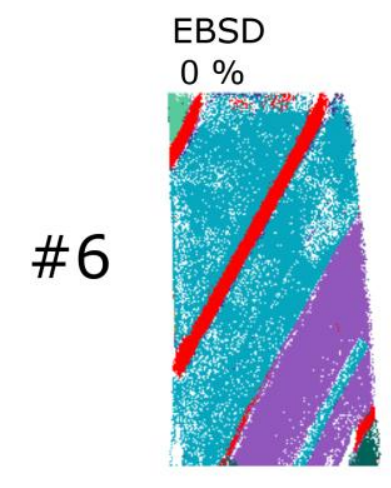

(a)

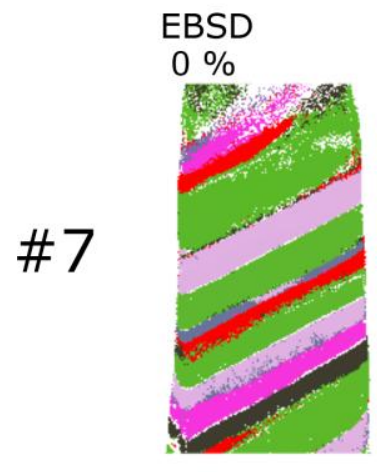

(d)

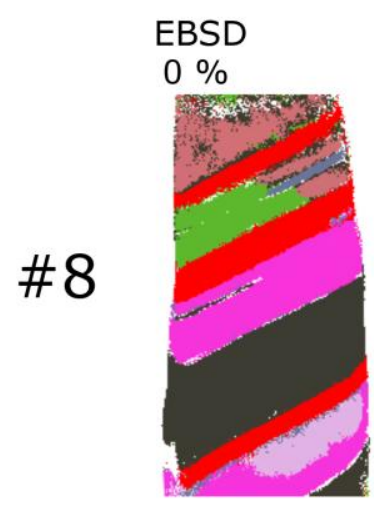

(g)

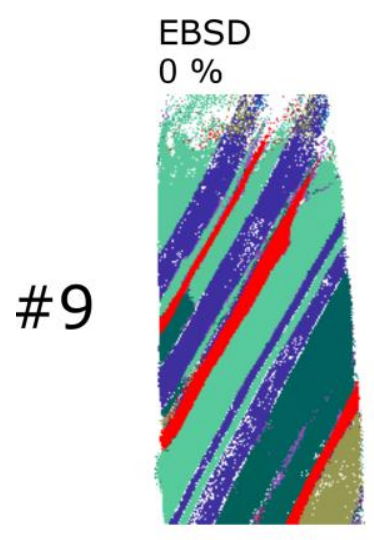

(j)

\section{$700^{\circ} \mathrm{C}$}

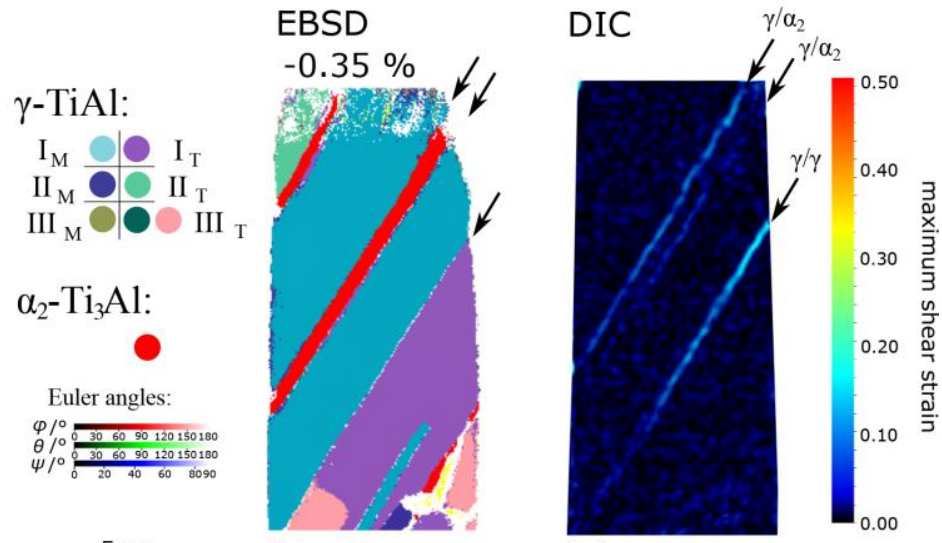

(b)

(c)

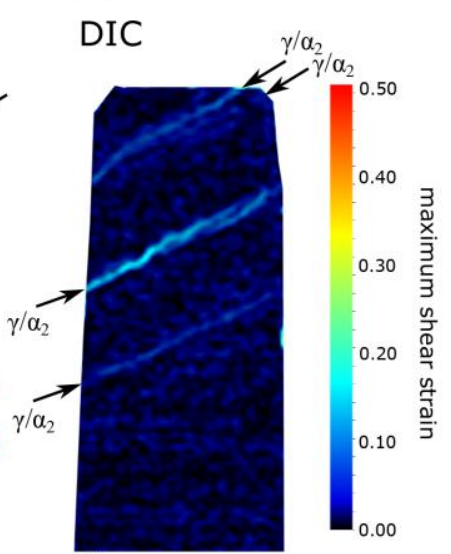

(e)

(f)

\section{EBSD}

$-0.72 \%$

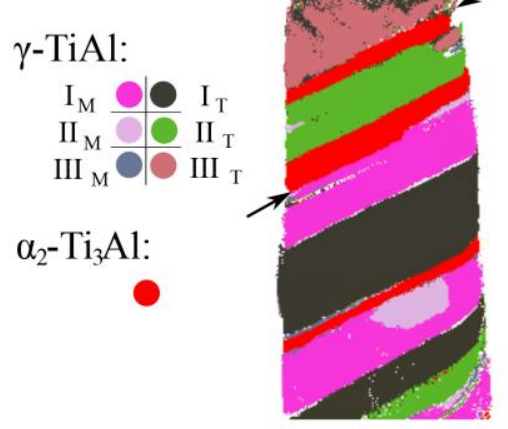

(h)

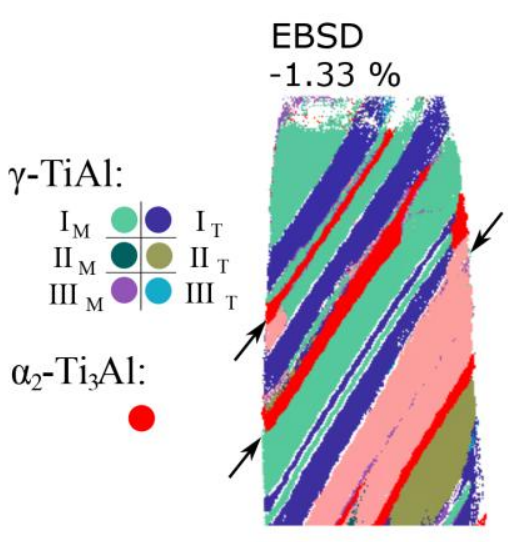

(k)

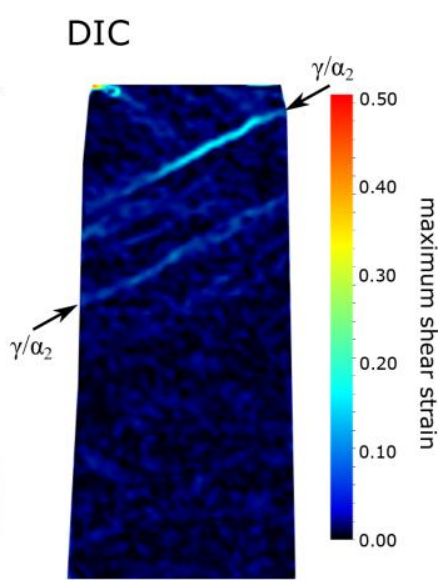

(i)

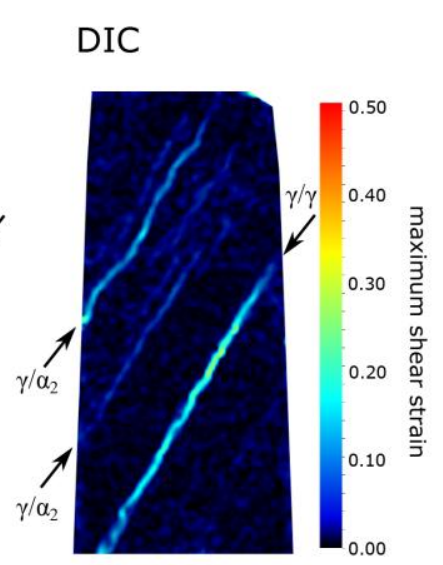

(1)

Figure 13 Pre- and post-compression EBSD maps, and DIC strain maps for the micropillars compressed at $700{ }^{\circ} \mathrm{C}$. Arrows have the same meaning as in Fig. 11. 

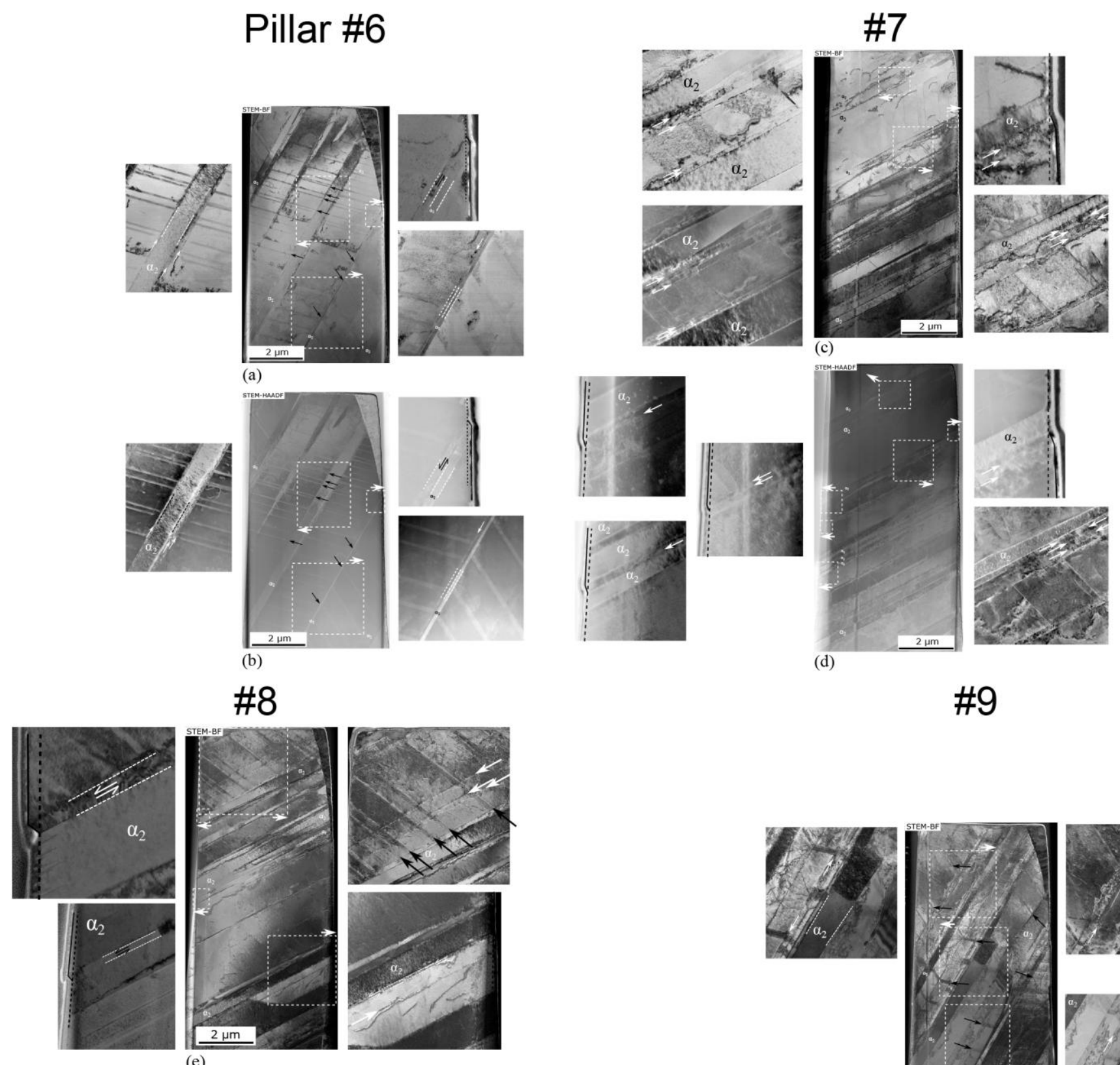

\#8
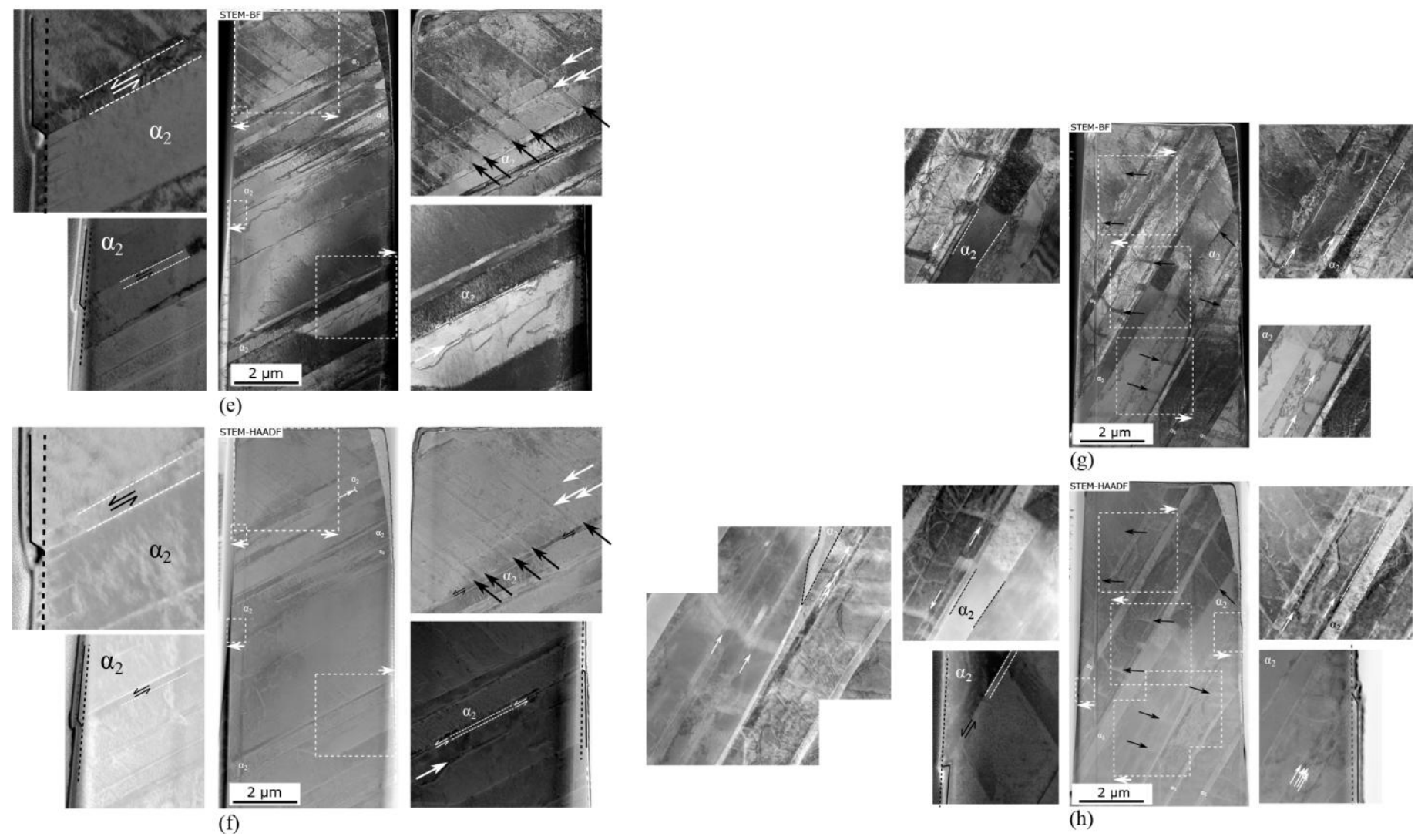

Figure 14 STEM BF (a,c,e,g) and HAADF (b,d,f,h) images of thin foil lift-outs of the pillars compressed at $700{ }^{\circ} \mathrm{C}$ in Fig. 13. All annotated carry the same meaning as in Fig. 12. (a,b) is pillar 6, (c,d) 7, (e,f) 8 and (g,h) 9 . 